\title{
Chemical Differentiation of Genetically Identified Atractylodes japonica, $A$. macrocephala, and A. chinensis Rhizomes Using High-Performance Liquid Chromatography with Chemometric Analysis
}

\author{
Jung-Hoon Kim $(\mathbb{D}),{ }^{1}$ Eui-Jeong Doh $\mathbb{D}^{2},{ }^{2,3}$ and Guemsan Lee $\mathbb{D}^{2}$ \\ ${ }^{1}$ Division of Pharmacology, School of Korean Medicine, Pusan National University, Yangsan 50612, Republic of Korea \\ ${ }^{2}$ Department of Herbology, College of Korean Medicine, Wonkwang University, Iksan 54538, Republic of Korea \\ ${ }^{3}$ Research Center of Traditional Korean Medicine, Wonkwang University, Iksan 54538, Republic of Korea \\ Correspondence should be addressed to Jung-Hoon Kim; kmsct@pusan.ac.kr and Guemsan Lee; rasfin@wku.ac.kr
}

Received 23 May 2018; Revised 8 July 2018; Accepted 10 July 2018; Published 2 August 2018

Academic Editor: Juntra Karbwang

Copyright (c) 2018 Jung-Hoon Kim et al. This is an open access article distributed under the Creative Commons Attribution License, which permits unrestricted use, distribution, and reproduction in any medium, provided the original work is properly cited.

\begin{abstract}
The rhizome of Atractylodes japonica, which is a herbal medicine used for gastrointestinal therapeutics, has been categorized with A. macrocephala rhizome or A. chinensis rhizome based on different therapeutic criteria in Korea, China, and Japan. In the present study, 61 A. japonica, A. macrocephala, and A. chinensis rhizomes were collected from Korea and China and were genetically identified by internal transcribed spacer sequencing analysis. Chromatographic profiles were obtained from high-performance liquid chromatography analysis of the methanol and hot-water extracts of Atractylodes rhizomes and chemical differentiation of the rhizomes was carried out using chemometric statistical analyses such as principal component analysis, hierarchical clustering analysis, and Pearson's correlation coefficient analysis. The results from chromatographic profiles and chemometric analyses demonstrate that $A$. japonica rhizomes showed apparent chemical differences from A. macrocephala and A. chinensis rhizomes in the methanol extracts. In contrast, no clear distinction was apparent for the hot-water extracts of Atractylodes rhizomes, especially A. chinensis rhizomes. These results indicate that there is a clear chemical difference between $A$. japonica and A. macrocephala rhizomes; however, the chemical diversity of $A$. chinensis rhizome shows different chemical relationships with A. japonica or $A$. macrocephala rhizome, dependent on the chemical features.
\end{abstract}

\section{Introduction}

The rhizomes of Atractylodes japonica, A. macrocephala, and A. chinensis (Asteraceae) have been therapeutically used to treat gastrointestinal disorders in Korea, China, and Japan. The medicinal classification of these rhizomes differs in the pharmacopeia of each country: the rhizomes of $A$. japonica and $A$. macrocephala are categorized together in Korea, while the rhizome of $A$. japonica is unofficial in the pharmacopeia but is categorized with that of $A$. chinensis in China [13]. This inconsistency, especially with respect to A. japonica rhizome, causes confusion in the use of the Atractylodes rhizomes between countries with different categorization of such medicinal herbs.
For the criteria of the use of Atractylodes rhizomes, we reported in our previous study that the rhizome of $A$. japonica showed a closer genetic relationship and higher chemical similarity with $A$. chinensis rhizome than with $A$. macrocephala rhizome, and more consistent therapeutic effects would be expected when similarly categorized. Therefore, we proposed that $A$. japonica rhizome is genetically and chemically distinct from $A$. macrocephala rhizome and that the former should be used under the same medicinal categorization as A. chinensis rhizome [4]. However, there were a number of limitations at study, such as insufficient sample numbers, a lack of detailed sample information, and single solvent extraction. Hence, genetic and chemical relationships 
among Atractylodes rhizomes should be evaluated under improved conditions.

In the present study, a total of 61 Atractylodes samples were collected and their original species were identified using internal transcribed spacer (ITS) sequences from nuclear ribosomal DNA (nrDNA), which is the identification method mostly used for genetic confirmation of plant species [5-7]. Genetically identified samples were extracted with either organic or aqueous solvents, and the extracts were analyzed using a high-performance liquid chromatographydiode array detector (HPLC-DAD) instrument to compare their chromatographic profiles [8]. The chemical relevance of the rhizomes of A. japonica, A. macrocephala, and $A$. chinensis was determined based on principal component analysis (PCA), hierarchical clustering analysis (HCA), and Pearson's correlation analysis.

\section{Materials and Methods}

2.1. Plant Materials and Reagents. Methanol, water, and acetonitrile (HPLC grade) were purchased from J.T.Baker (Phillipsburg, NJ, USA). Trifluoroacetic acid (TFA) was purchased from Sigma-Aldrich (St Louis, MO, USA). Fortyone samples of $A$. japonica rhizomes, 11 samples of $A$. macrocephala rhizomes, and 9 samples of $A$. chinensis rhizomes were obtained from the wild, agricultural fields, or local herbal markets in Korea and China in 2016. The samples were authenticated by their morphological characteristics and by ITS sequencing analysis. The samples were coded as AJ for $A$. japonica rhizomes, AM for A. macrocephala rhizomes, and AC for A. chinensis rhizomes (Table 1). Voucher specimens have been deposited at the School of Korean Medicine, Pusan National University.

2.2. Preparation of Genomic DNA. Genomic DNA was extracted from the crude drugs of Atractylodes rhizomes according to the modified manuals of NucleoSpin ${ }^{\circledR}$ Plant II kit (Macherey-Nagel, Dueren, Germany). For some samples, $10 \%$ cetyltrimethyl ammonium bromide and $0.7 \mathrm{M} \mathrm{NaCl}$ were used to remove the phenolic compounds and polysaccharides.

2.3. PCR Amplification. For ITS amplification, PCR was performed using a T-personal cycler (Biometra; Göttingen, Germany). Briefly, $600 \mathrm{nM}$ of the primer set of ITS1 $\left(5^{\prime}\right.$-TCCGTAGGTGAACCTGCGG- $\left.3^{\prime}\right)$ and ITS4 (5' - TCCTCCGCTTATTGATATGC-3' ${ }^{\prime}$ [9], AccuPower ${ }^{\circledR}$ GoldHotstart Taq PCR PreMix (Bioneer, Daejeon, Korea), and 50 ng of genomic DNA were used for PCR amplification. PCR cycling conditions, which were followed by predenaturation process $\left(95^{\circ} \mathrm{C}, 5 \mathrm{~min}\right)$, were as follows: denaturation process $\left(95^{\circ} \mathrm{C}, 30 \mathrm{~s}\right)$; annealing progress $\left(52^{\circ} \mathrm{C}, 30 \mathrm{~s}\right)$; extension process $\left(72^{\circ} \mathrm{C}, 40 \mathrm{~s}\right) \times 36$ cycles; final extension process $\left(72^{\circ} \mathrm{C}, 5 \mathrm{~min}\right)$. The amplified PCR product was separated from other gradients by using $1.5 \%$ agarose gel electrophoresis after staining by the addition of SafeView ${ }^{\mathrm{TM}}$ (abm; Vancouver, Canada). Amplified products were analyzed using MyImage (Seoulin Biotechnology; Seongnam, Gyeonggi-do, Korea).
2.4. Determination of DNA Sequence of PCR Product. PCR product separated from agarose gel was cloned by using a TOPcloner ${ }^{\text {TM }}$ TA-Blunt kit (Enzynomics, Daejeon, Korea) and the DNA sequence of the cloned PCR product was determined after interpretation performed by Bioneer (Daejeon, Korea).

2.5. Analysis of DNA Sequence and Preparation of Dendrogram. DNA sequences were analyzed using the ClustalW multiple sequence alignment (BioEdit, v7.0.9; available at http://www.mbio.ncsu.edu/BioEdit/page2.html) and the phylogenetic tree was created using DNADist (BioEdit). To study the relationships among Atractylodes rhizomes, the nucleotide sequences of the genera Atractylis and Carlina deposited in NCBI GenBank were used. The genera Brachylaena, Cardopatium, Cirsium, Echinops, Phonus, and Tarchonanthus were used as outgroups in the phylogenetic analyses, based on previous studies [10, 11]. ITS sequences of these taxa were collected from NCBI GenBank. The ITS sequences of nine specimens (coded with Arabic numerals) of Atractylodes plants were collected as species reference samples for identification of Atractylodes rhizomes in previous research [4], and these were used as a reference for species.

2.6. Preparation of Samples for HPLC Analysis. For the methanol extract, dried powder of the rhizomes $(1.0 \mathrm{~g})$ was extracted with $10 \mathrm{~mL}$ of methanol using an ultrasonic extractor (Power Sonic 520; Hwashin Tech, Daegu, Korea) for $30 \mathrm{~min}$. The extract was centrifuged at $10,000 \mathrm{rpm}$ for $5 \mathrm{~min}$. The supernatant was transferred to a $1.5 \mathrm{~mL}$ microtube and evaporated using a nitrogen gas blowing concentrator (MGS-2200; Eyela, Miyagi, Japan). Residue was dissolved in methanol to a concentration of $10,000 \mu \mathrm{g} / \mathrm{mL}$ and the extract solution was filtered through a $0.2 \mu \mathrm{m}$ syringe filter (BioFact; Daejeon, Korea) prior to HPLC injection.

For the hot-water extract, dried powder of the rhizome $(0.5 \mathrm{~g})$ was extracted in a $100 \mathrm{~mL}$ glass bottle with $20 \mathrm{~mL}$ of distilled water using a microwave oven (BP-111RS; Microwave Research \& Applications, Inc., IL, USA) at $90^{\circ} \mathrm{C}$ for $20 \mathrm{~min}$. The water extract was transferred to a $15 \mathrm{~mL}$ conical tube and centrifuged at $3000 \mathrm{rpm}$ for $10 \mathrm{~min}$. The supernatant was lyophilized using a freeze-dryer (IlShinBioBase; Dongducheon, Gyeonggi-do, Korea). The powder of dried extract $(20 \mathrm{mg}$ ) was dissolved in $1 \mathrm{~mL}$ of HPLC grade water and then the solution was centrifuged at $10,000 \mathrm{rpm}$ for $5 \mathrm{~min}$. The supernatant was filtered through a $0.2 \mu \mathrm{m}$ syringe filter (BioFact) prior to HPLC injection.

\subsection{HPLC Conditions for Chromatographic Fingerprinting.} An Agilent 1260 liquid chromatography system (Agilent Technologies; Palo Alto, CA, USA) equipped with an autosampler, degasser, quaternary solvent pump, and diode array detector (DAD) was used for chromatographic fingerprinting. The data were processed with Chemstation software (Agilent Technologies). The separation of compounds was carried out on a Capcell Pak Mg II C 18 column $(4.6 \mathrm{~mm} \times$ $250 \mathrm{~mm}, 5 \mu \mathrm{m}$; Shiseido, Tokyo, Japan) at $35^{\circ} \mathrm{C}$. The flow rate was $1 \mathrm{~mL} / \mathrm{min}$ and the injection volume was $10 \mu \mathrm{L}$. 
TABLE 1: Genetically original species and collecting area of Atractylodes samples.

\begin{tabular}{|c|c|c|c|c|c|c|c|}
\hline Code & Location & Country & Date of collection & Code & Location & Country & Date of collection \\
\hline AJ1 & $\begin{array}{l}\text { Euiseong, } \\
\text { Gyeongbuk }\end{array}$ & Korea & Jan, 2016 & AJ32 & $\begin{array}{l}\text { Yeongdeok, } \\
\text { Gyeongbuk }\end{array}$ & Korea & Feb, 2016 \\
\hline $\mathrm{AJ} 2$ & - & Korea & Feb, 2016 & AJ33 & $\begin{array}{l}\text { Yeongcheon, } \\
\text { Gyeongbuk }\end{array}$ & Korea & Feb, 2016 \\
\hline $\mathrm{AJ} 3$ & $\begin{array}{l}\text { Euiseong, } \\
\text { Gyeongbuk }\end{array}$ & Korea & Feb, 2016 & AJ34 & $\begin{array}{c}\text { Yangpyeong, } \\
\text { Gyeonggi }\end{array}$ & Korea & Feb, 2016 \\
\hline $\mathrm{AJ} 4$ & - & Korea & Jan, 2016 & AJ35 & $\begin{array}{l}\text { Hongcheon, } \\
\text { Gangwon }\end{array}$ & Korea & Feb, 2016 \\
\hline AJ5 & $\begin{array}{l}\text { Yeongdeok, } \\
\text { Gyeongbuk }\end{array}$ & Korea & Feb, 2016 & AJ36 & $\begin{array}{c}\text { Andong, } \\
\text { Gyeongbuk }\end{array}$ & Korea & Feb, 2016 \\
\hline AJ6 & - & Korea & Jan, 2016 & AJ37 & $\begin{array}{l}\text { Yeongcheon, } \\
\text { Gyeongbuk }\end{array}$ & Korea & Feb, 2016 \\
\hline AJ7 & $\begin{array}{l}\text { Bonghwa, } \\
\text { Gyeongbuk }\end{array}$ & Korea & Feb, 2016 & AJ38 & $\begin{array}{l}\text { Cheongsong, } \\
\text { Gyeongbuk }\end{array}$ & Korea & Feb, 2016 \\
\hline AJ8 & $\begin{array}{l}\text { Yeongcheon, } \\
\text { Gyeongbuk }\end{array}$ & Korea & Feb, 2016 & AJ39 & Neimengu & China & Apr, 2016 \\
\hline AJ9 & $\begin{array}{l}\text { Yeongcheon, } \\
\text { Gyeongbuk }\end{array}$ & Korea & Feb, 2016 & $\mathrm{AJ} 40$ & Hebei & China & Jul, 2016 \\
\hline AJ10 & - & Korea & Mar, 2016 & AJ41 & - & China & Aug, 2016 \\
\hline AJ11 & - & China & Jan, 2016 & AM1 & - & China & Jan, 2016 \\
\hline AJ12 & - & China & Jan, 2016 & AM2 & Anhui & China & Jul, 2016 \\
\hline AJ13 & $\begin{array}{l}\text { Yeongwol, } \\
\text { Gangwon }\end{array}$ & Korea & Feb, 2016 & AM3 & - & China & Jan, 2016 \\
\hline AJ14 & Hwasun, Jeonnam & Korea & Jan, 2016 & AM4 & Zhejiang & China & Mar, 2016 \\
\hline AJ15 & Heilongjiang & China & Mar, 2016 & AM5 & Zhejiang & China & Feb, 2014 \\
\hline AJ16 & - & Korea (North) & Jan, 2016 & AM6 & - & China & Jan, 2016 \\
\hline AJ17 & - & Korea & Jan, 2016 & AM7 & - & China & Jan, 2016 \\
\hline AJ18 & $\begin{array}{l}\text { Yeongdeok, } \\
\text { Gyeongbuk }\end{array}$ & Korea & Jan, 2016 & AM8 & Shanghai & China & Jul, 2016 \\
\hline AJ19 & - & Korea & Jan, 2016 & AM9 & Panan, Zhejiang & China & Jul, 2016 \\
\hline AJ20 & - & China & Jan, 2016 & AM10 & Panan, Zhejiang & China & Jul, 2016 \\
\hline AJ21 & - & China & Jan, 2016 & AM11 & - & China & Aug, 2016 \\
\hline AJ22 & Heilongjiang & China & Jan, 2016 & $\mathrm{AC} 1$ & Hubei & China & Mar, 2016 \\
\hline AJ23 & Suwon, Gyeonggi & Korea & Jan, 2016 & AC2 & - & China & Jan, 2016 \\
\hline AJ24 & Jangsu, Jeonbuk & Korea & Jan, 2016 & $\mathrm{AC} 3$ & Chengde, Hebei & China & Jul, 2016 \\
\hline AJ25 & $\begin{array}{l}\text { Yangsan, } \\
\text { Gyeongnam }\end{array}$ & Korea & Oct, 2016 & AC4 & - & China & Jan, 2016 \\
\hline AJ26 & $\begin{array}{l}\text { Cheongyang, } \\
\text { Chungnam }\end{array}$ & Korea & May, 2016 & AC5 & Chengde, Hebei & China & Jul, 2016 \\
\hline AJ27 & Heilongjiang & China & Aug, 2016 & AC6 & Hebei & China & Jul, 2016 \\
\hline AJ28 & $\begin{array}{l}\text { Yeongcheon, } \\
\text { Gyeongbuk }\end{array}$ & Korea & Feb, 2016 & AC7 & Neimengu & China & Mar, 2014 \\
\hline AJ29 & $\begin{array}{l}\text { Yeongcheon, } \\
\text { Gyeongbuk }\end{array}$ & Korea & Feb, 2016 & AC8 & - & China & Jan, 2016 \\
\hline AJ30 & - & Korea & Feb, 2016 & AC9 & - & China & Jan, 2016 \\
\hline AJ31 & $\begin{array}{l}\text { Jecheon, } \\
\text { Chungbuk }\end{array}$ & Korea & Feb, 2016 & & & & \\
\hline
\end{tabular}

AJ, Atractylodes japonica; AM, A. macrocephala; AC, A. chinensis. “-”: unclear location. 
For analysis of the methanol extract, the mobile phase consisted of water (A) and acetonitrile (B), with the following gradient elution: $55 \%$ (B) over $0-1 \mathrm{~min}, 55-60 \%$ (B) over $1-35 \mathrm{~min}, 60 \%$ (B) over $35-36 \mathrm{~min}, 60-90 \%$ (B) over 36-51 min, 90\% (B) over 51-52 min, and then reequilibration to $55 \%$ (B) until the end of the analysis. Detection was performed with a UV detector at wavelengths of 230, 255, 275, 315 , and $340 \mathrm{~nm}$.

For analysis of the hot-water extract, the mobile phase consisted of $0.1 \%$ TFA in water (A) and acetonitrile (B), with the following gradient elution: $5 \%$ (B) over $0-5 \mathrm{~min}, 5-40 \%$ (B) over 5-35 min, 40\% (B) over 35-36 min, 40-70\% (B) over 36-51 min, 70\% (B) over 51-52 min, and then reequilibration to $5 \%$ (B) until the end of the analysis. Detection was performed with a UV detector at wavelengths of $225,255,275$, 295, and $325 \mathrm{~nm}$.

2.8. Chemometric Statistical Analysis. The 61 samples that were genetically identified and recoded were used for PCA, $\mathrm{HCA}$, and Pearson's correlation analysis. In total, 45 and 31 peaks were selected as reference peaks $(>1.0 \%$ of total peak area) for the methanol extract and water extract, respectively, at their optimal UV absorption, and their absolute areas were calculated by peak area integration for chromatographic fingerprinting. A matrix composed of the rows (Atractylodes sample) and columns (absolute area of each reference peak) was used to construct the PC plot and dendrogram and for Pearson's correlation analysis, using the open source software R (v. 3.4.3; The R Foundation for Statistical Computing).

\section{Results}

3.1. ITS Genotype and Genetic Identification of Atractylodes Rhizomes. Amplification of the ITS region produced overall $733 \mathrm{bp}$ of nucleotide sequences from 61 samples listed in Table 1 and from nine dried voucher specimens [4]. The ITS sequences of samples were determined by comparing DNA sequences registered in NCBI GenBank as well as in [12], with the following accession numbers: for $A$. japonica AB219405, for A. macrocephala AB219406, for A. lancea AB219407, for A. chinensis AB219408, and for A. koreana AB219409. As shown in previous research [4], nucleotide substitutions were observed in 37 sites on the ITS regions of Atractylodes samples. Type 1, the ITS sequence of A. japonica, showed multiple sequences compared with the other species; Types 2 and 3 were the genotypes of $A$. macrocephala and $A$. lancea, respectively. Type 4 , the genotype of $A$. chinensis, was identical to Type 5 , the genotype of $A$. koreana.

All 11 samples labeled AM, were determined as A. macrocephala; no difference of DNA sequence between samples was observed. Among the nine samples labeled AC, determined as A. chinensis, $\mathrm{AC} 4, \mathrm{AC} 7$, and $\mathrm{AC} 8$ showed differences in nucleotide sequence. The sequence of AC4, AC7, and AC8 differed from that of Type 4 by $1 \mathrm{bp}(\mathrm{A} \longrightarrow \mathrm{G})$ at nucleotide position $128 \mathrm{bp}$, which indicates intraspecific variation. All 41 samples labeled $\mathrm{AJ}$ were determined as A. japonica. Unlike in other species, some intraspecific variation was observed among the $41 \mathrm{AJ}$ samples. Most of the differences were multisequences, which have already been shown to be Type 1 [4].

3.2. Genetic Relationship of the Atractylodes Rhizomes. Sixtyone samples of Atractylodes rhizomes were identified as $A$. chinensis, A. japonica, and A. macrocephala. Phylogenetic classifications based on the ITS region were made and the inferred evolutionary relationships among Atractylodes rhizomes are represented as a phylogenetic tree. The genus Atractylodes is well separated from other close genera and outgroups. The samples of A. japonica, A. lancea, and A. chinensis formed $A$. lancea complex, whereas those of $A$. macrocephala formed their own A. macrocephala complex (Figure 1).

3.3. Chromatographic Profiling of the Methanol and Hot-Water Extracts of Atractylodes Samples. Chromatographic profiles of representative samples (AJ1, ACl, and AM1) at all UV wavelengths were compared; a total of 45 peaks and 31 peaks for the methanol and water extracts, respectively, were selected for comparison by macroscopic observation and further chemometric analysis (Figures 2 and 3 and Table S1). There were distinct differences in chromatographic patterns of the methanol extracts of $\mathrm{AJ}, \mathrm{AC}$, and $\mathrm{AM}$, and 28 out of 45 reference peaks were shared among the methanol extracts of Atractylodes samples (Figure 4). In contrast, chromatographic differences among the water extracts were less distinctive, with 18 out of 31 references peaks being shared among the chromatograms from the hot-water extracts (Figure 5).

3.4. Clustering Analysis of Atractylodes Samples Using Chemometric Statistical Methods. Chromatographic profiles of the methanol and water extracts from Atractylodes samples were further analyzed by principal component analysis (PCA), hierarchical clustering analysis (HCA), and of Pearson's correlation coefficient to estimate the relationship between the Atractylodes samples.

In the principal component (PC) plot of the methanol extracts of the samples, three distinct clusters were observed: an AJ group (AJ1-41 including AC4), an AM group (AM1-10), and an AC group (AC1-9 except AC4). The distribution of $\mathrm{PCl}$ score showed that the samples in the AJ group were plotted closer to those in the AM group than those in the AC group; in contrast, in the PC2 score, the samples in the AC group were located closer to those in the AJ group than those in the AM group (Figure 6). However, the PC plot of the hot-water extracts of the samples differed from that of the methanol extracts. As the samples were distributed in a wide range of $\mathrm{PC} 1$ and $\mathrm{PC} 2$ scores, no distinct clusters were observed. AC4 and AC6 were plotted closer to the location of AJ samples, whereas AC5 and AC8 overlapped into the plots of AM samples (Figure 7).

The dendrogram of methanol extracts from HCA showed similar groups as obtained from PCA; namely, AJ, AC, and AM samples formed their own groups (groups II, III, and IV) except for AC4 in the AJ group. However, several AJ samples were divided into a separate group below a height of 250000 and clustered in group I below a height of 100000 


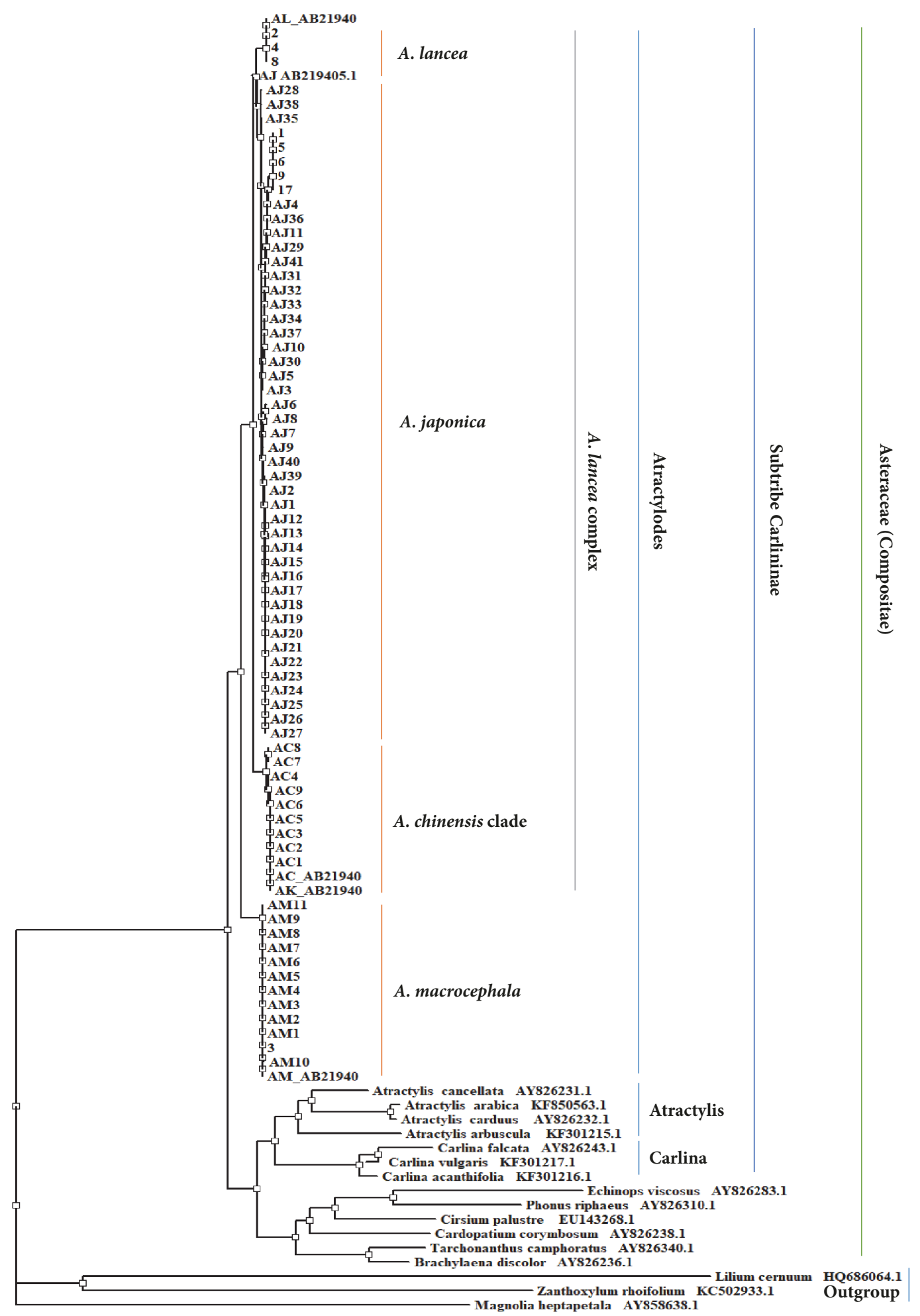

0.1

FIGURE 1: Phylogenic tree from DNADist (neighbor phylogenetic tree) analysis of the ITS nucleotide sequences. The ITS sequences of taxa with Atractylis, Carlina, and Outgroup were downloaded from NCBI GenBank. The samples with Arabic numerals were dried voucher specimens deposited at the Korea Institute of Oriental Medicine. 


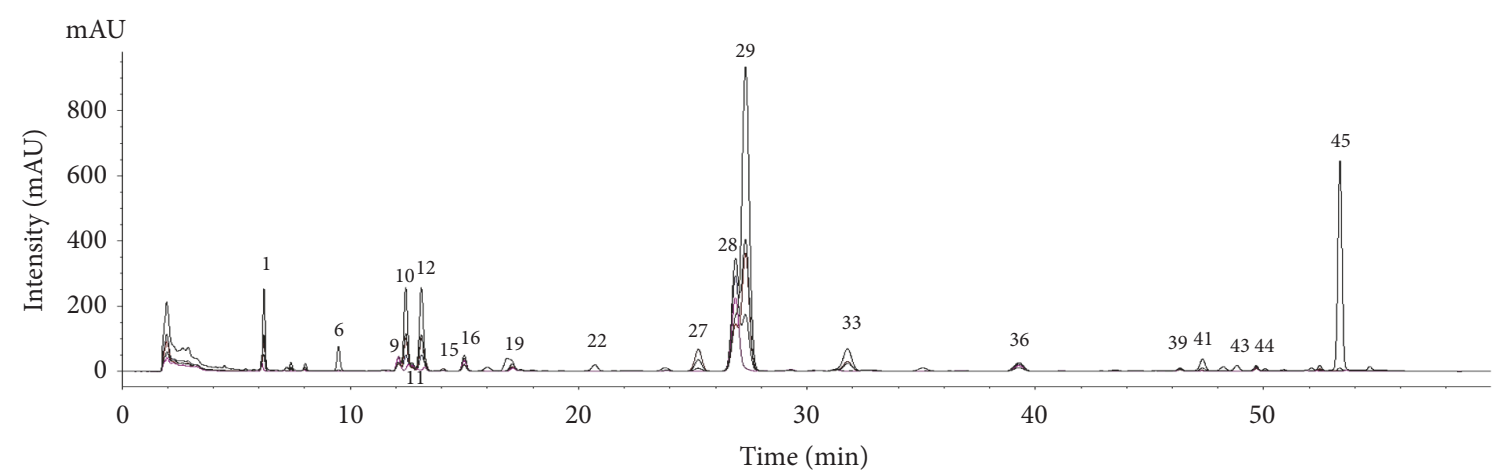

(a)

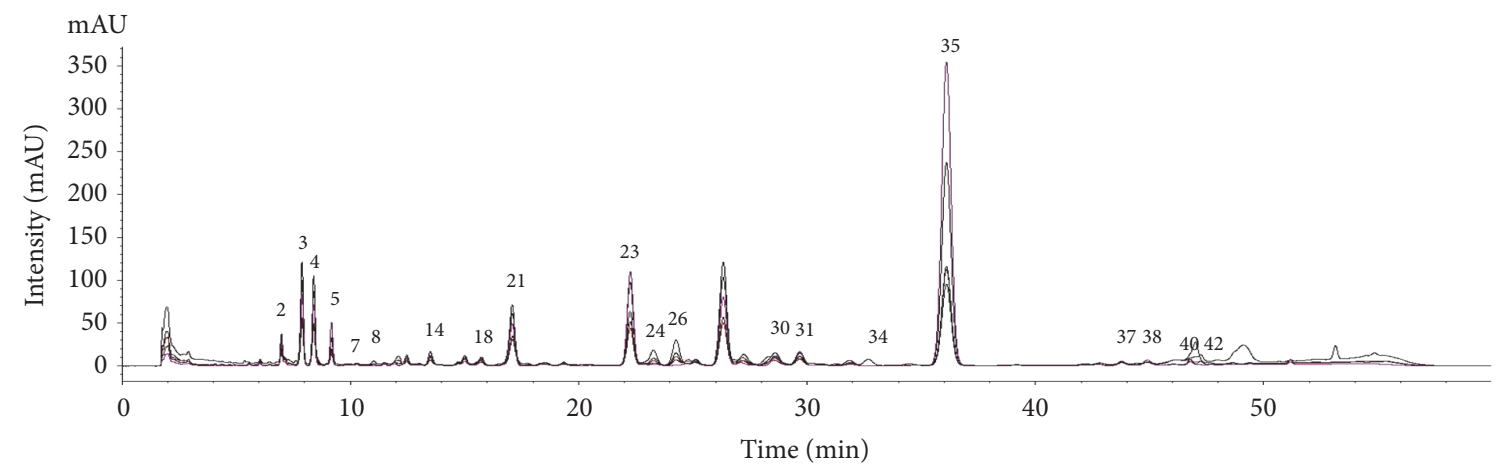

(b)

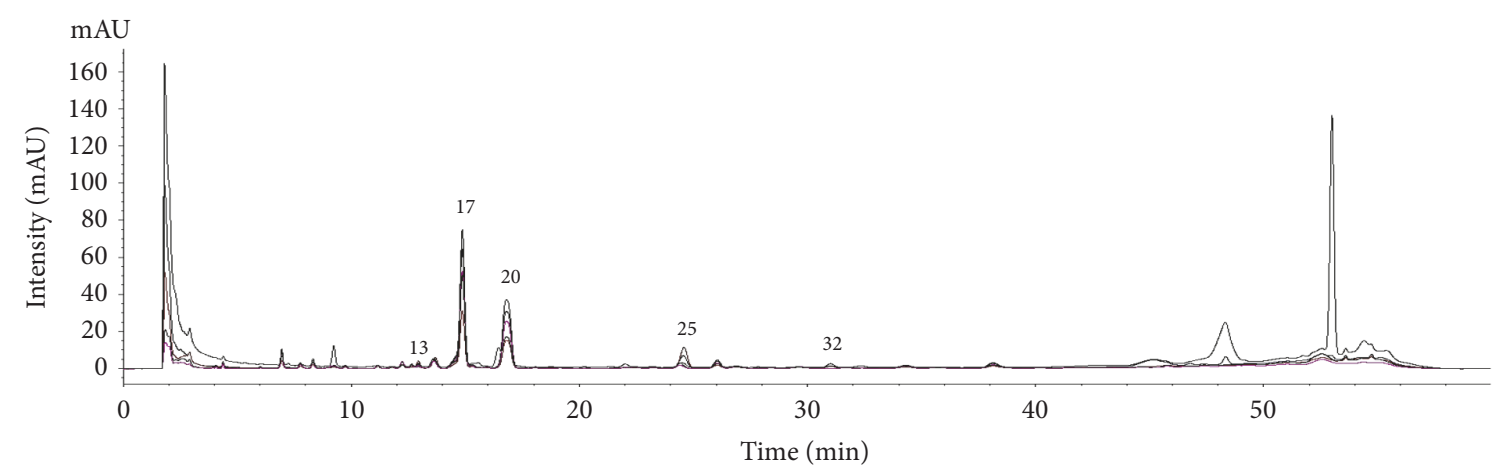

(c)

FIGURE 2: Representative chromatograms of methanol extracts of Atractylodes japonica (AJ1, (a)), A. chinensis (AC1, (b)), and A. macrocephala (AM1, (c)) at UV wavelengths of 230, 255, 275, 315, and $340 \mathrm{~nm}$.

(Figure 8). For the dendrogram of the methanol extracts, the water extracts of AJ samples were also divided into two distinct groups (groups I and II), whereas those of AC and AM samples were not clearly distinguished within their own groups because they were not separated in the subgroup of group II, below a height of 4000 (Figure 9).

3.5. Evaluation of the Correlation between A. japonica, A. chinensis, and A. macrocephala Samples by Pearson's Correlation Coefficient. In the methanol extracts, the mean value of the Pearson's correlation coefficient $(r)$ of each AJ sample ranged from 0.01 to 0.31 (except for AJ41; $r=-0.01$ ) for the correlation of AM samples and from 0.01 to 0.1 for the correlation of AC samples (Figure 10(a)). The mean correlation coefficient of each AC sample ranged from -0.08 to 0.1 (except for AC4; $r=$ 0.95 ) for the correlation of AJ samples and from -0.07 to 0.1 for the correlation of AM samples (Figure 10(b)). The mean correlation coefficient of each AM sample ranged from -0.05 to -0.01 for the correlation of AC samples and from -0.03 to 0.22 for the correlation of AJ samples (Figure 10(c)).

In the hot-water extracts, the mean correlation coefficient of each AJ sample ranged from 0.25 to 0.80 for the correlation of AM samples and from 0.30 to 0.81 for the correlation of AC samples (Figure 11(a)). The mean correlation coefficient of each AC sample ranged from 0.55 to 0.72 for the correlation of AJ samples and from 0.29 to 0.87 for the correlation of AM samples (Figure 11(b)). The mean correlation coefficient of each AM sample ranged from 0.49 to 0.79 for the correlation 


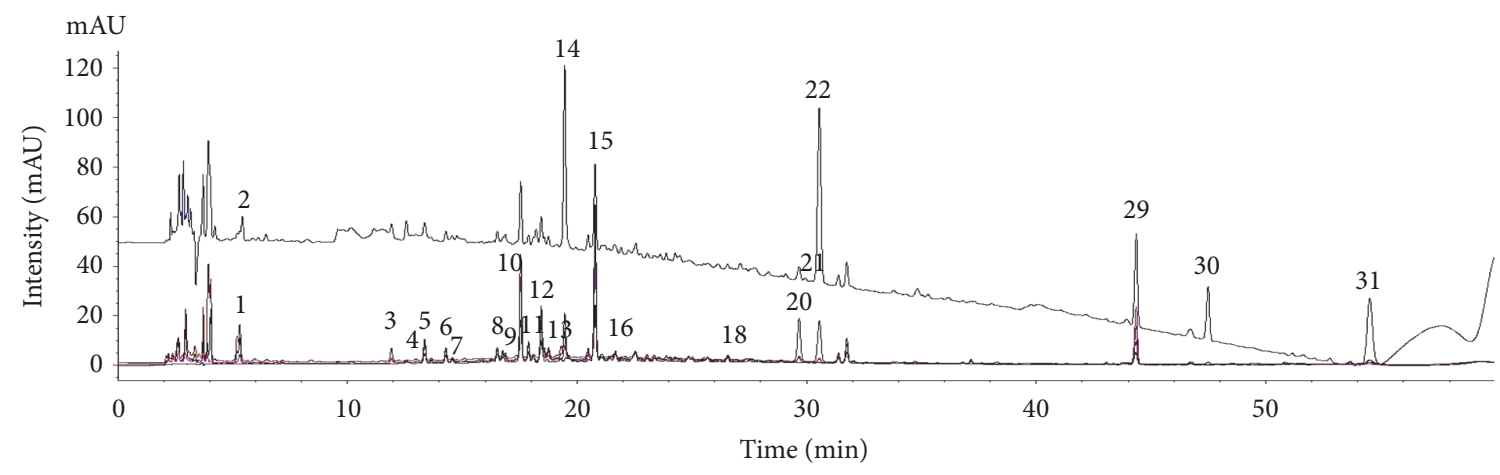

(a)

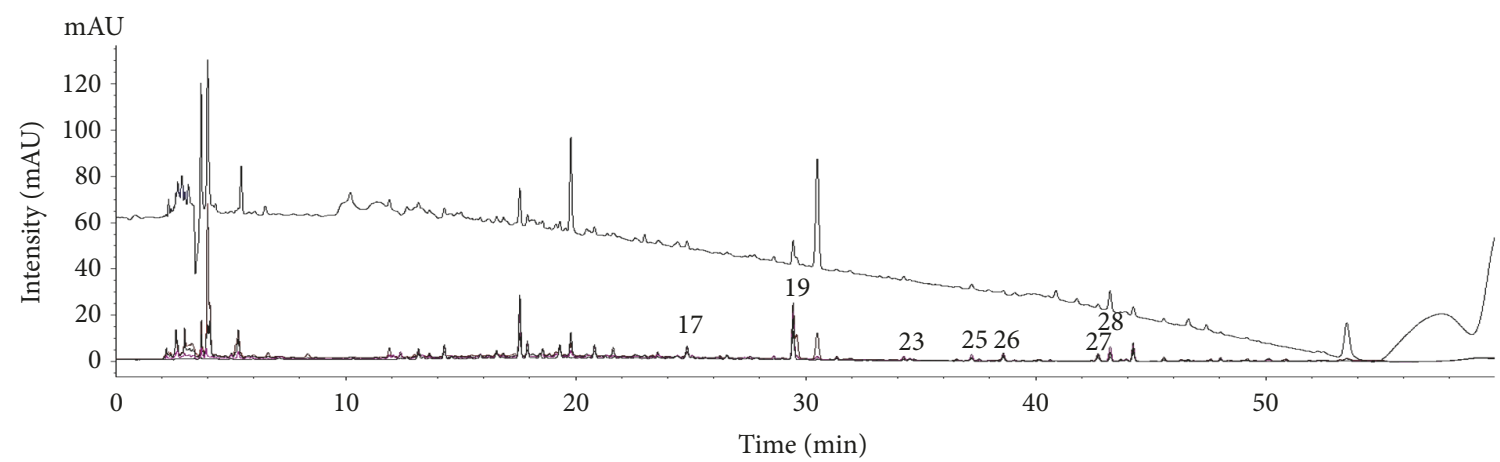

(b)

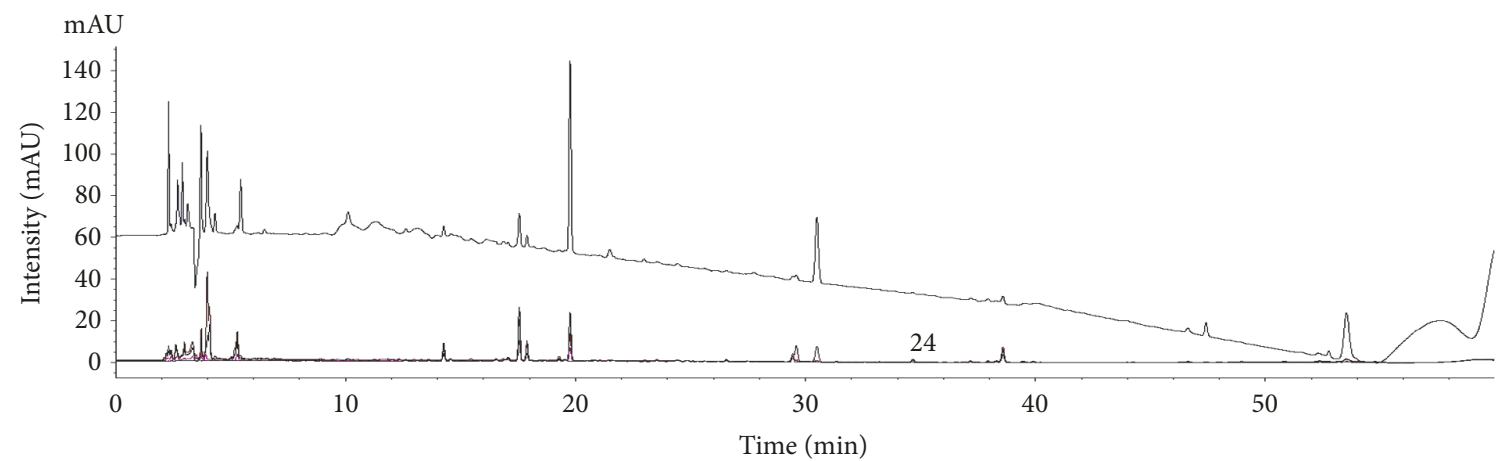

(c)

Figure 3: Representative chromatograms of hot-water extracts of A. japonica (AJ1, (a)), A. chinensis (AC1, (b)), and A. macrocephala (AM1, (c)) at UV wavelengths of $225,255,275,295$, and $325 \mathrm{~nm}$.

of AC samples and from 0.45 to 0.65 for the correlation of AJ samples (Figure 11(c)). The mean and median values of Pearson's correlation coefficient from Atractylodes samples are shown in Table 2.

\section{Discussion}

We previously proposed that the rhizome of $A$. japonica (AJ) should be considered for medicinal use as being in the same medicinal category as that of A. chinensis (AC) because of their genetic and chemical similarity to that of A. macrocephala (AM) [4]. However, an unresolved issue is whether the rhizome of $A$. japonica should be medicinally used in parallel with the rhizome of $A$. macrocephala or with the rhizome of $A$. chinensis. Therefore, building on our previous work, in this study, 61 Atractylodes rhizomes that were collected from Korea and China in 2016 were genetically identified by their original species and their chemical differentiation was carried out by chromatographic profiling and chemometric statistical analysis.

In the methanol extracts, three apparent clusters of Atractylodes samples in the PC plot (AJ samples + AC4, AC samples, and AM samples) showed different proximity among each group. PC1 and PC2 scores, the most and next most influential factors of clustering in the PC plot, provided the group of $\mathrm{AJ}$ samples with more proximity to the group of AM samples than that of AC samples which results in better chemical relevance, as the PC scores of the AJ samples were closer to those of AM samples $[13,14]$. The proximity among the groups of AJ, AC, and AM samples was also confirmed 


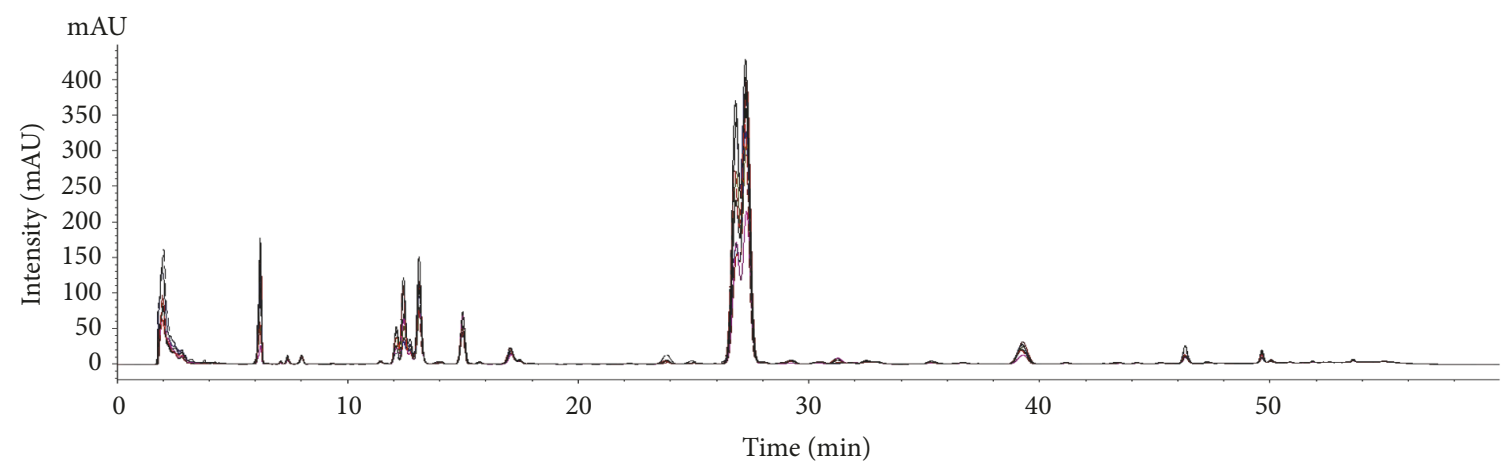

(a)

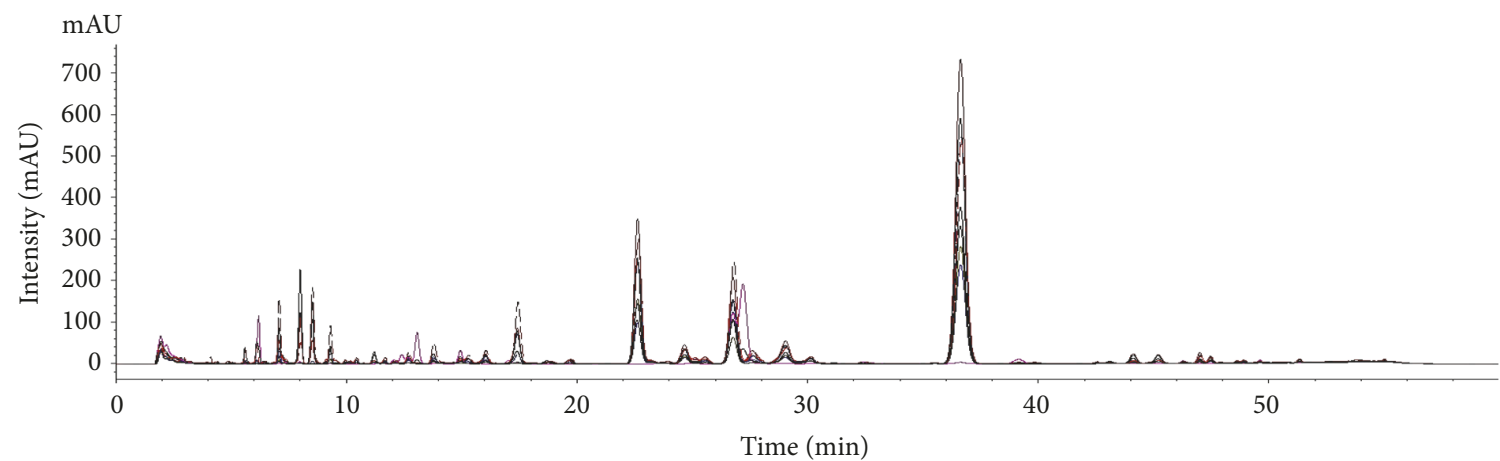

(b)

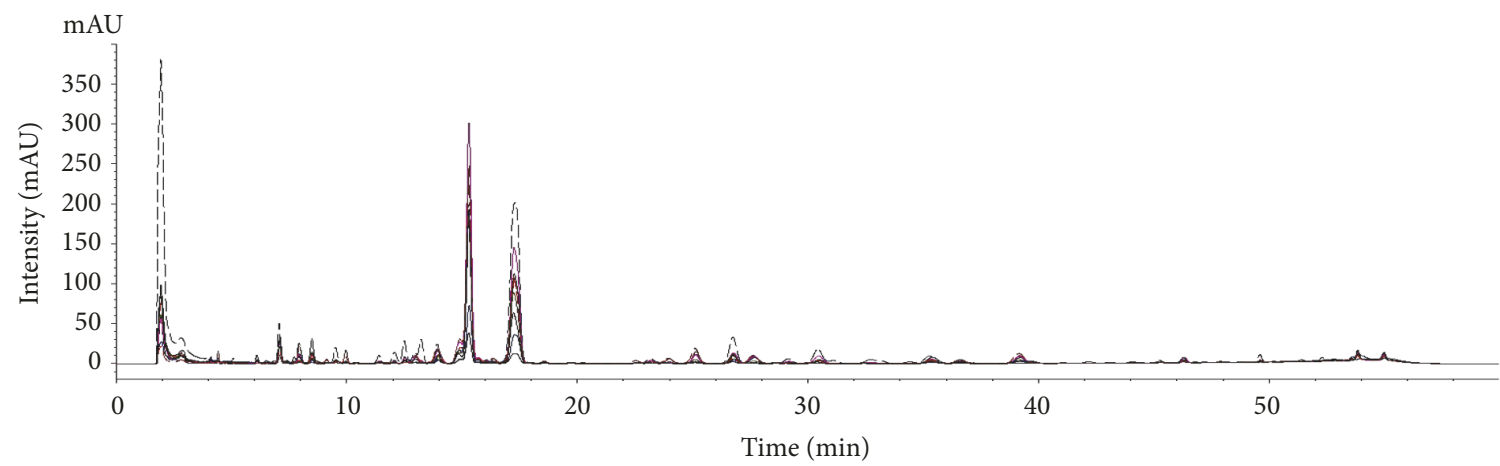

(c)

FIGURE 4: Representative chromatograms of methanol extracts of A. japonica (AJ1-9, (a)), A. chinensis (AC1-9, (b)), and A. macrocephala (AM1-9, (c)) at UV wavelength of $315 \mathrm{~nm}$.

by the dendrogram from HCA, which produces clusters to classify samples by measuring the distance between samples $[15,16]$. The dendrogram also indicated apparent groups of $\mathrm{AJ}, \mathrm{AC}$, and AM samples, and samples in the AJ group (cluster IV) showed closer chemical similarity to those in the AM group (cluster III) than to those in the AC group (cluster II) below a height of 100000 , as samples with a similar distance were involved in the same group [17].

Pearson's correlation coefficient $(r)$ analysis among the samples also supports the clusters obtained from PCA and HCA. The overall correlation between different Atractylodes species was not strong and was even negative, indicating that the samples of AJ, AM, and AC groups represented a weak correlation and, hence, were separated from each other $[18,19]$. Stronger correlation was observed between samples from the AJ-AM group, with positive and higher $r$ values, than between samples from the AJ-AC group, with negative and lower $r$ values (close to 0 ) [20,21].

In the hot-water extracts, the clusters of the samples according to their original species were not distinct in the PC plot, in which the samples from the same species were mostly gathered together. The AJ samples exhibited higher chemical similarity to a number of AC samples from the most influential PC1 scores, whereas the PC2 scores of AJ samples indicated a closer relationship to AM samples. Rather, AC and AM samples showed higher proximity to each other. These relationships between samples were also observed in the dendrogram: the AJ samples formed separate groups, whereas the $\mathrm{AC}$ and $\mathrm{AM}$ samples were consolidated in subgroups of cluster II, which makes the apparent delineation 


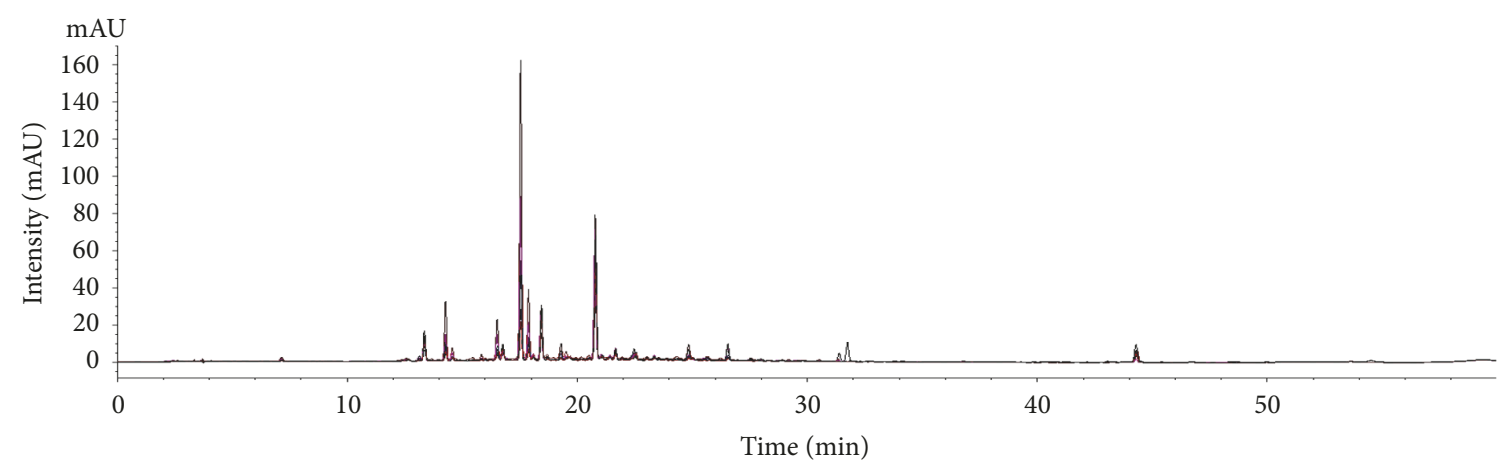

(a)

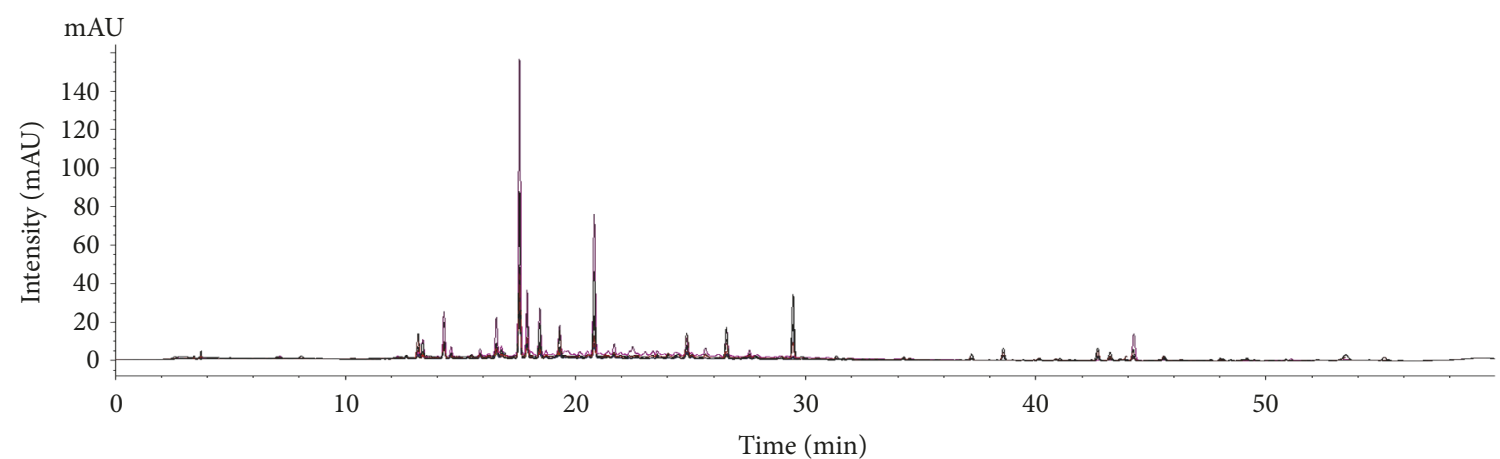

(b)

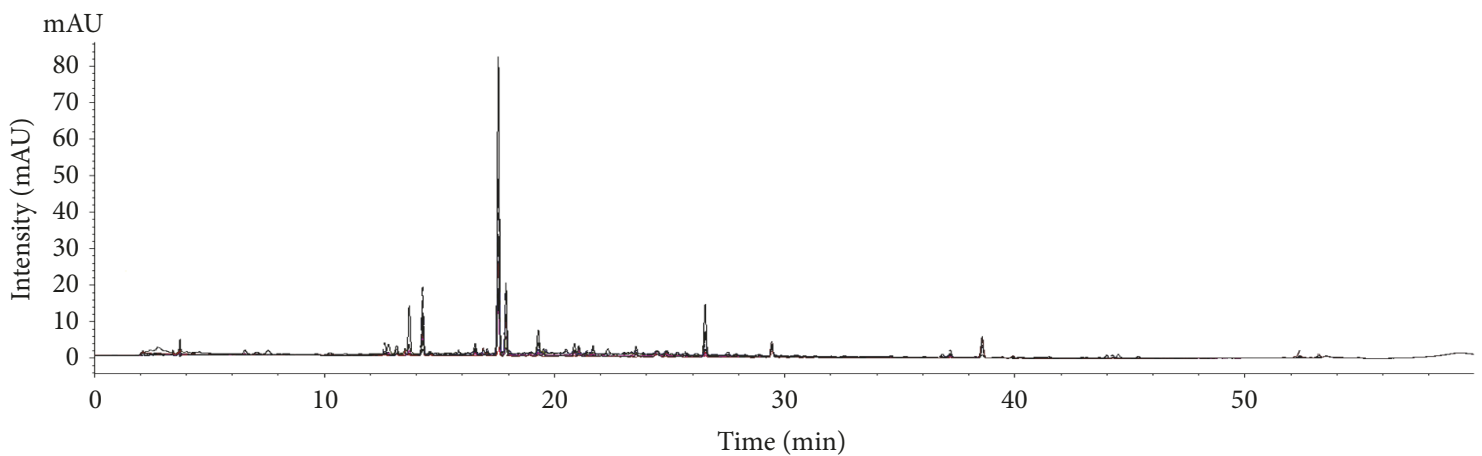

(c)

Figure 5: Representative chromatograms of hot-water extracts of A. japonica (AJ1-9, (a)), A. chinensis (AC1-9, (b)), and A. macrocephala (AM1-9, (c)) at UV wavelength of $325 \mathrm{~nm}$.

between AC and AM samples more difficult, as evaluated by the higher $r$ values between two species. Moreover, AJ samples indicated a stronger correlation with AC samples than with AM samples overall.

Unlike the distribution of the samples in the PC plot, about half of the AJ samples formed a separate AJ group (each cluster $\mathrm{I}$ in the dendrograms from the methanol and water extracts, respectively) in the dendrogram from HCA, showing least similarity with $\mathrm{AC}, \mathrm{AM}$, and the remaining $\mathrm{AJ}$ samples. In contrast, but similar to the results from PCA, each AJ sample was strongly correlated with other AJ samples from the methanol and hot-water extracts, with an $r$ value close to 1 [19] (Supplementary Figures S1 and S2). These results might be ascribed to the differences in mathematical and statistical methods between HCA and PCA [22-24].
In contrast to our previous study [4], the chemometric results of the present study demonstrate that the chemical correlation and relevance of AJ samples, particularly in the methanol extracts (organic extract), were weaker with AC samples than with AM samples, although AJ samples have a closer genetic relationship to $\mathrm{AC}$ samples than to $\mathrm{AM}$ samples. Regarding these results, an important difference from the previous work that should be considered, however, is that there was always a distance between AJ and AM samples in the previous and present study, which means that AJ samples were not chemically analogous to AM samples; that is, they had their own clusters of samples. Another point is that the location of AC samples changed from "inside" to "outside" the cluster of AJ samples, indicating that AC samples in the present work showed less chemical 


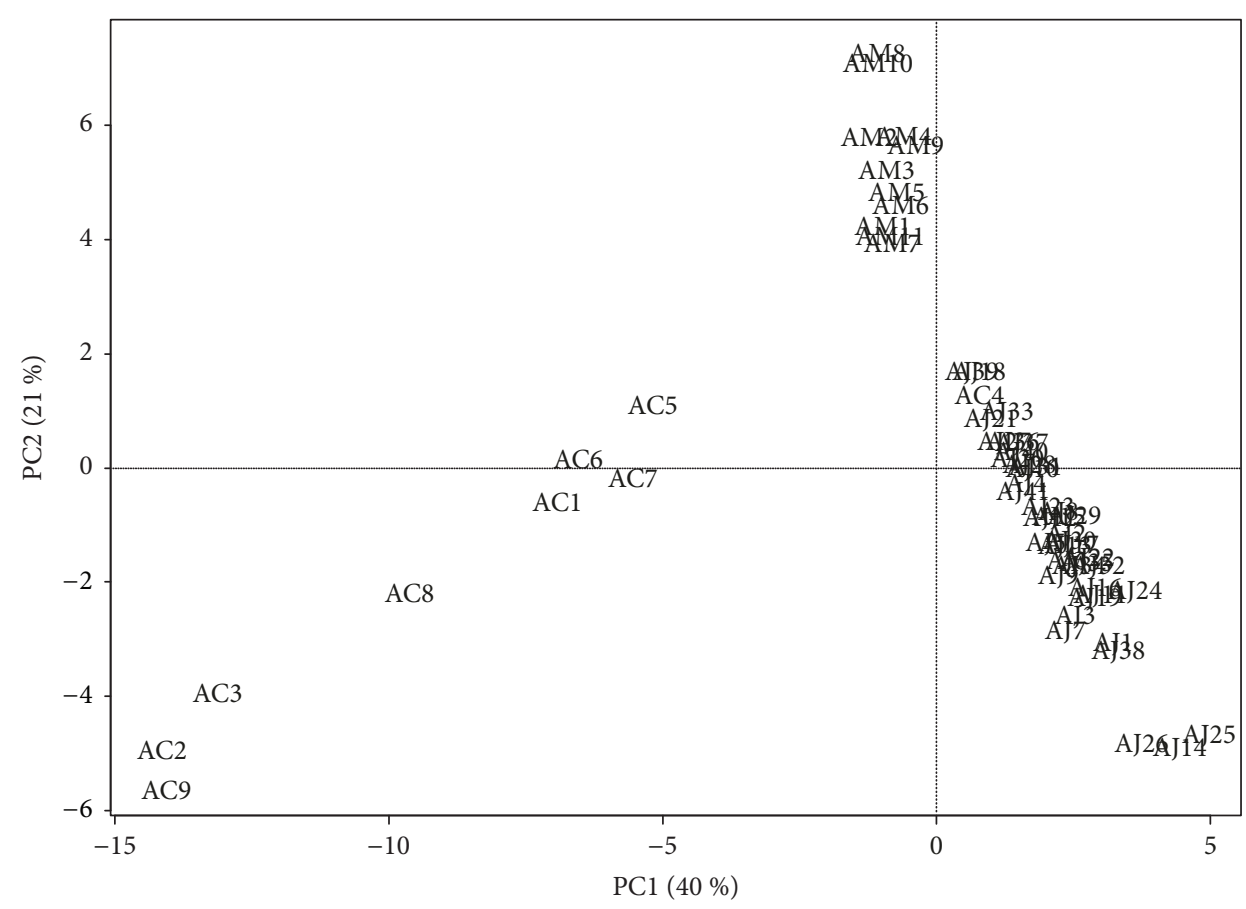

FIGURE 6: Score plot of principal components (PC1 versus PC2) on the variables (absolute area of reference peaks) with Atractylodes samples from the methanol extracts. PC1 and PC2 represent $40 \%$ and $21 \%$ of the total variance, respectively. AC: A. chinensis Koidz.; AJ: A. japonica Koidz.; AM: A. macrocephala Koidz.

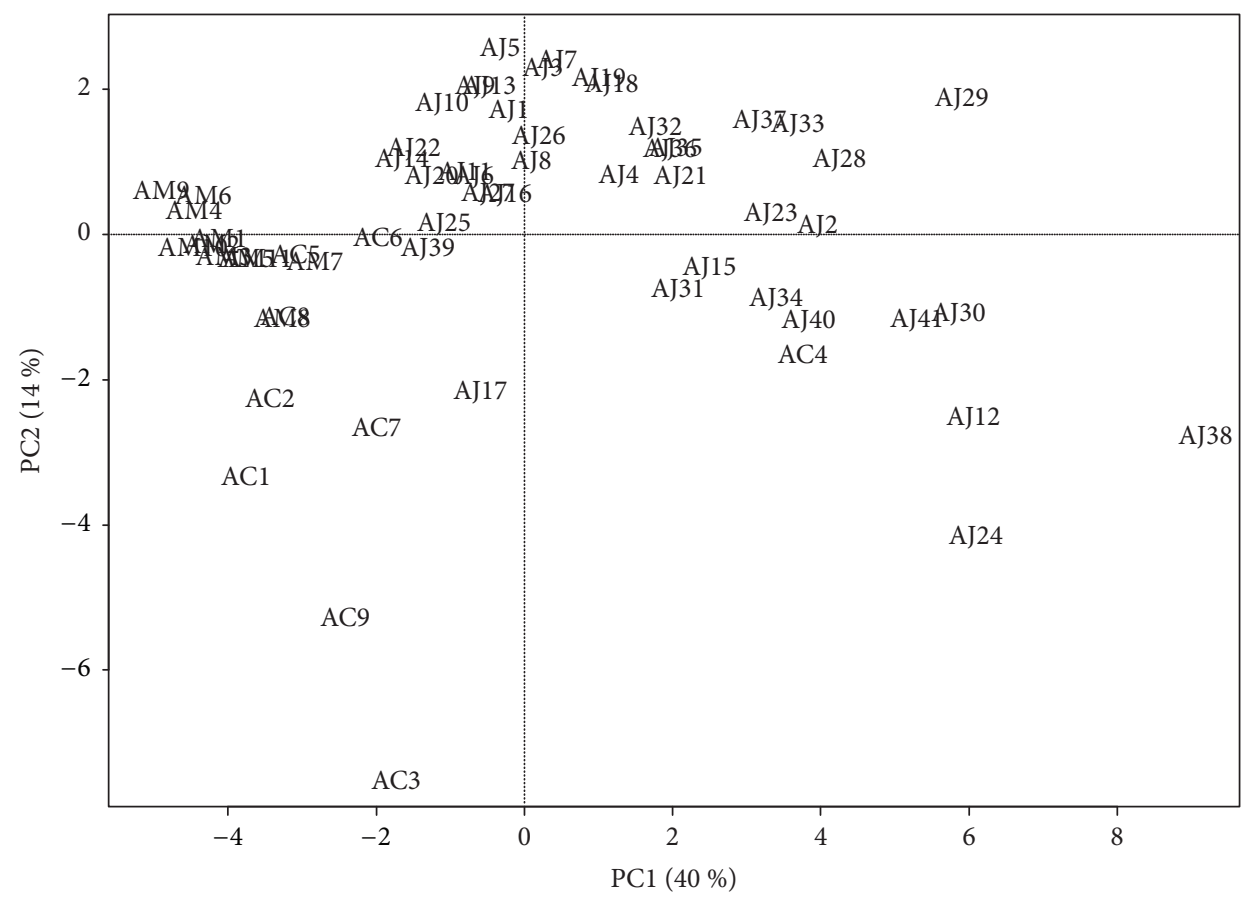

FIGURE 7: Score plot of principal components (PC1 versus PC2) on the variables (absolute area of reference peaks) with Atractylodes samples from the hot-water extracts. PC1 and PC2 represent $40 \%$ and 14\% of the total variance, respectively. AC: A. chinensis Koidz.; AJ: A. japonica Koidz.; AM: A. macrocephala Koidz. 


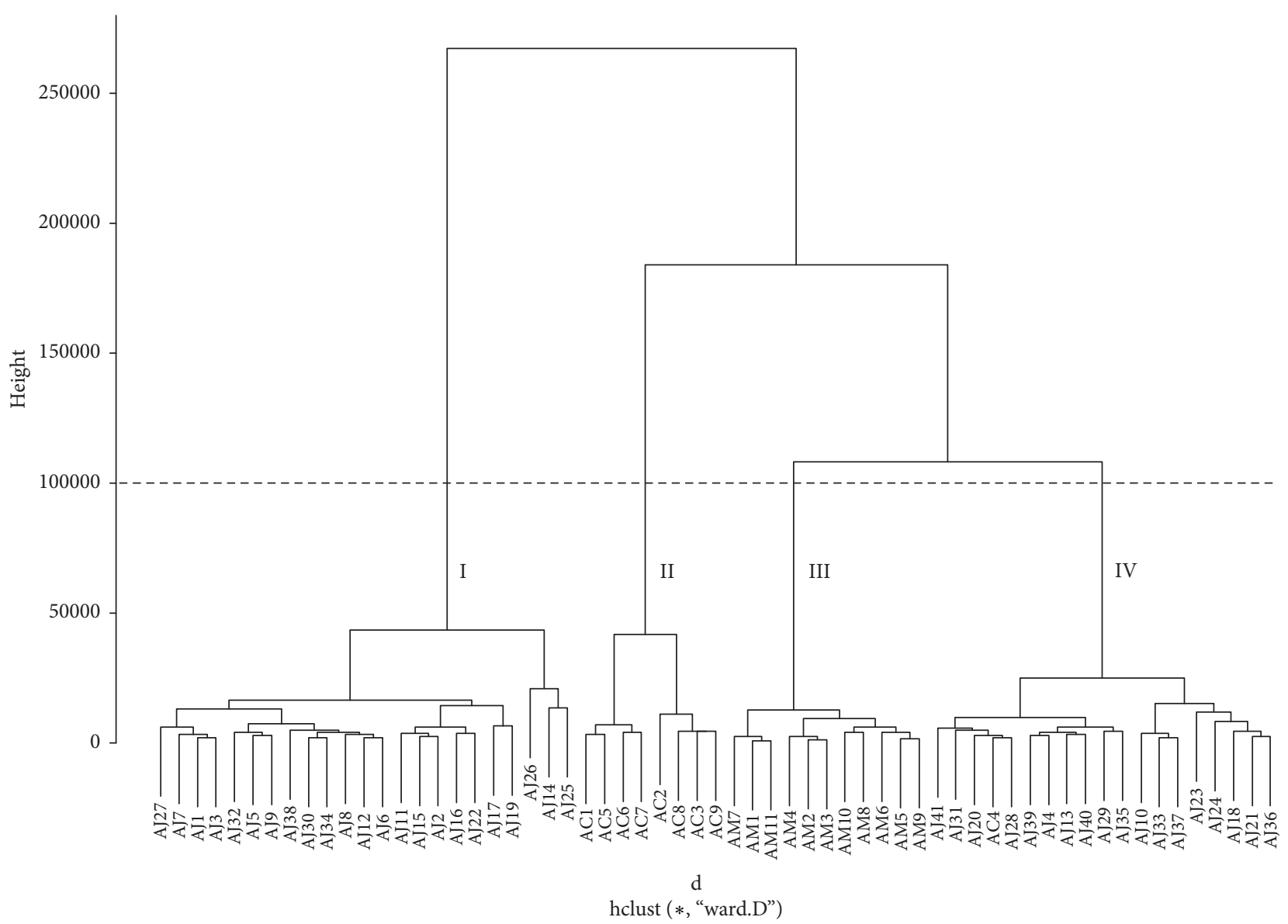

FIgURE 8: Hierarchical clustering analysis of Atractylodes samples from methanol extracts. AC: A. chinensis Koidz.; AJ: A. japonica Koidz.; AM: A. macrocephala Koidz.

homogeneity to AJ samples, as reported previously $[25,26]$. This might be explained by the fact that geographical diversity can lead to a wide range of variation in the content of chemical components from the rhizome of $A$. chinensis $[27,28]$. This is because environmental factors, such as climate, temperature, humidity, soil, and altitude, and the corresponding adaptation of plants are crucial for the biosynthesis and production of chemical components and secondary metabolites [29, 30], and such environmental differences can also influence the chemical variation in the plants of genus Atractylodes [31-34].

Based on the results from chromatographic profiles and chemometric analyses, A. japonica rhizomes could apparently be differentiated from A. macrocephala and A. chinensis rhizomes by their methanol-soluble components, whereas $A$. chinensis rhizomes were not clearly distinguishable from $A$. japonica and A. macrocephala rhizomes by their hot-watersoluble components. These results indicate that the chemical difference between $A$. japonica and A. macrocephala was distinct in both extracts, as also reported previously [4]. However, the difference between A. japonica and A. chinensis was dependent on the chemical features that were identified despite their closer genetic relationship. Moreover, aqueous components from $A$. chinensis rhizome were chemically closer to those from A. macrocephala rhizome, although they are categorized as different therapeutic agents. Further pharmacological and clinical evidence is necessary to confirm the chemical correlation between Atractylodes rhizomes.

\section{Conclusion}

In this study, 61 Atractylodes rhizomes that were collected from Korea and China in 2016 were genetically identified by their original species by ITS DNA sequencing analysis: A. japonica, A. macrocephala, and A. chinensis. Chemical differentiation was carried out by chromatographic profiling and chemometric statistical analysis, namely, PCA, HCA, and Pearson's correlation analysis, using the methanol and hot-water extracts of Atractylodes samples. The results from chemical fingerprinting and statistical analyses demonstrated that A. japonica rhizomes were chemically distinct from A. macrocephala rhizomes. However, A. chinensis rhizomes represented diverse chemical variation showing a wide range of relationships to A. japonica and A. macrocephala rhizomes, presumably arising from their environmental differences. 
TABLE 2: Mean and median value of Pearson's correlation coefficient $(r)$ among AJ, AM, and AC samples.

\begin{tabular}{|c|c|c|c|c|c|}
\hline \multirow{2}{*}{ Extraction } & \multirow{2}{*}{ Sample } & \multirow{2}{*}{ Parameter } & \multicolumn{3}{|c|}{ Correlation coefficient $(r)$} \\
\hline & & & $\mathrm{AJ}$ & $\mathrm{AM}$ & $\mathrm{AC}$ \\
\hline \multirow{6}{*}{ Methanol extract } & \multirow{2}{*}{ AJ } & Mean & - & 0.131 & 0.069 \\
\hline & & Median & - & 0.146 & -0.054 \\
\hline & \multirow{2}{*}{$\mathrm{AM}$} & Mean & 0.131 & - & -0.028 \\
\hline & & Median & 0.146 & - & -0.048 \\
\hline & \multirow{2}{*}{$\mathrm{AC}$} & Mean & 0.069 & -0.028 & - \\
\hline & & Median & -0.054 & -0.048 & - \\
\hline \multirow{6}{*}{ Water extract } & \multirow{2}{*}{$\mathrm{AJ}$} & Mean & - & 0.567 & 0.609 \\
\hline & & Median & - & 0.584 & 0.626 \\
\hline & \multirow{2}{*}{$\mathrm{AM}$} & Mean & 0.567 & - & 0.733 \\
\hline & & Median & 0.584 & - & 0.800 \\
\hline & \multirow{2}{*}{$\mathrm{AC}$} & Mean & 0.609 & 0.733 & - \\
\hline & & Median & 0.626 & 0.800 & - \\
\hline
\end{tabular}

AJ, A. japonica; AM, A. macrocephala; AC, A. chinensis.

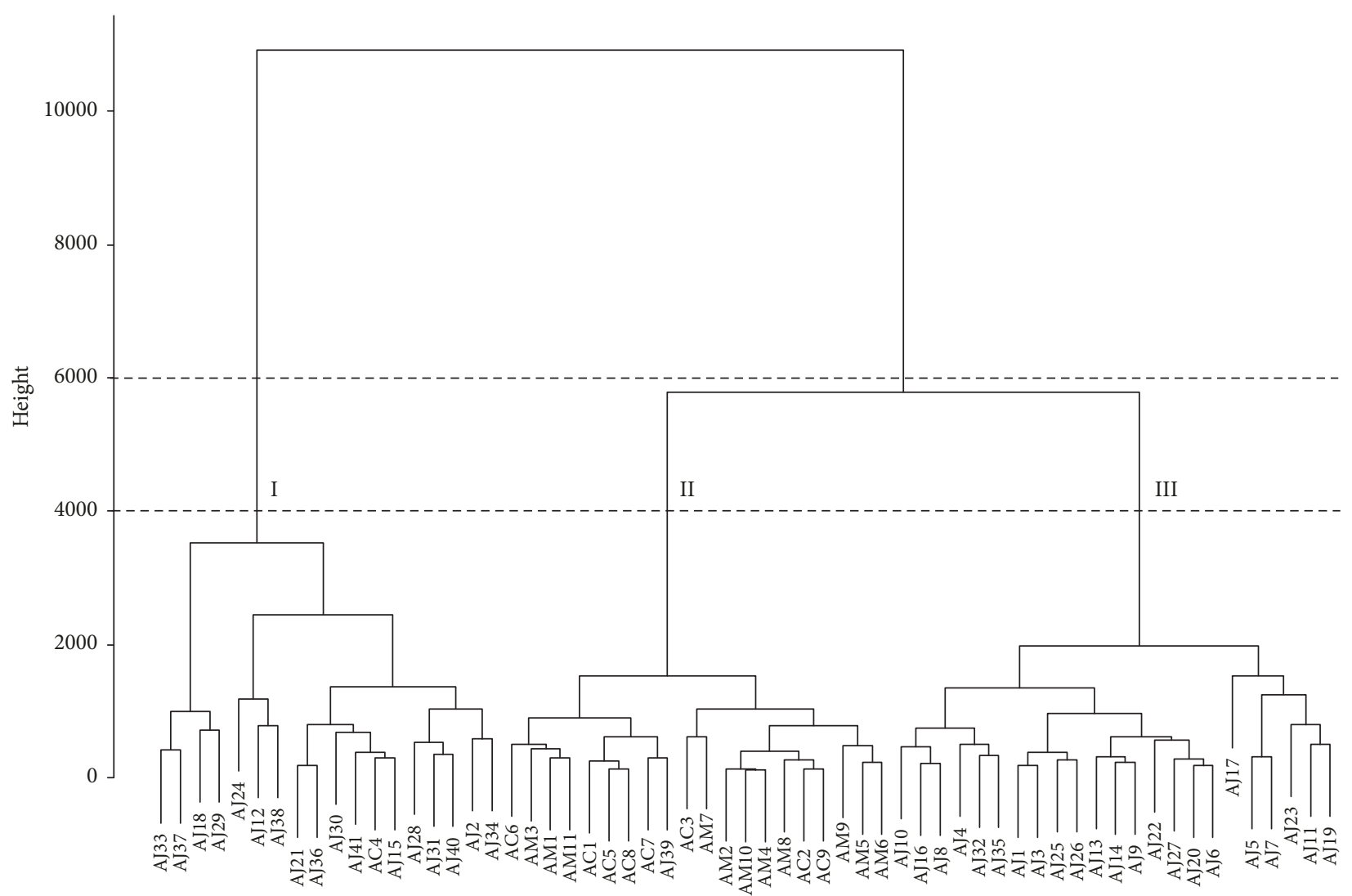

FIGURE 9: Hierarchical clustering analysis of Atractylodes samples from hot-water extracts. AC: A. chinensis Koidz.; AJ: A. japonica Koidz.; AM: A. macrocephala Koidz. 

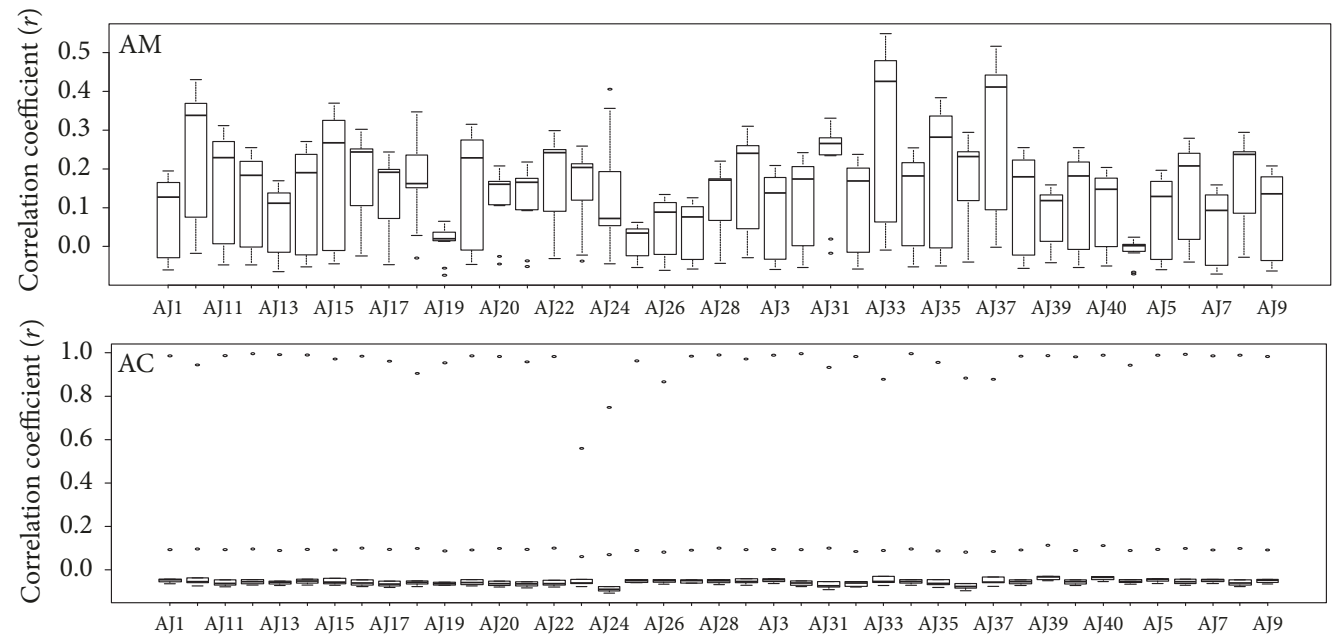

(a)
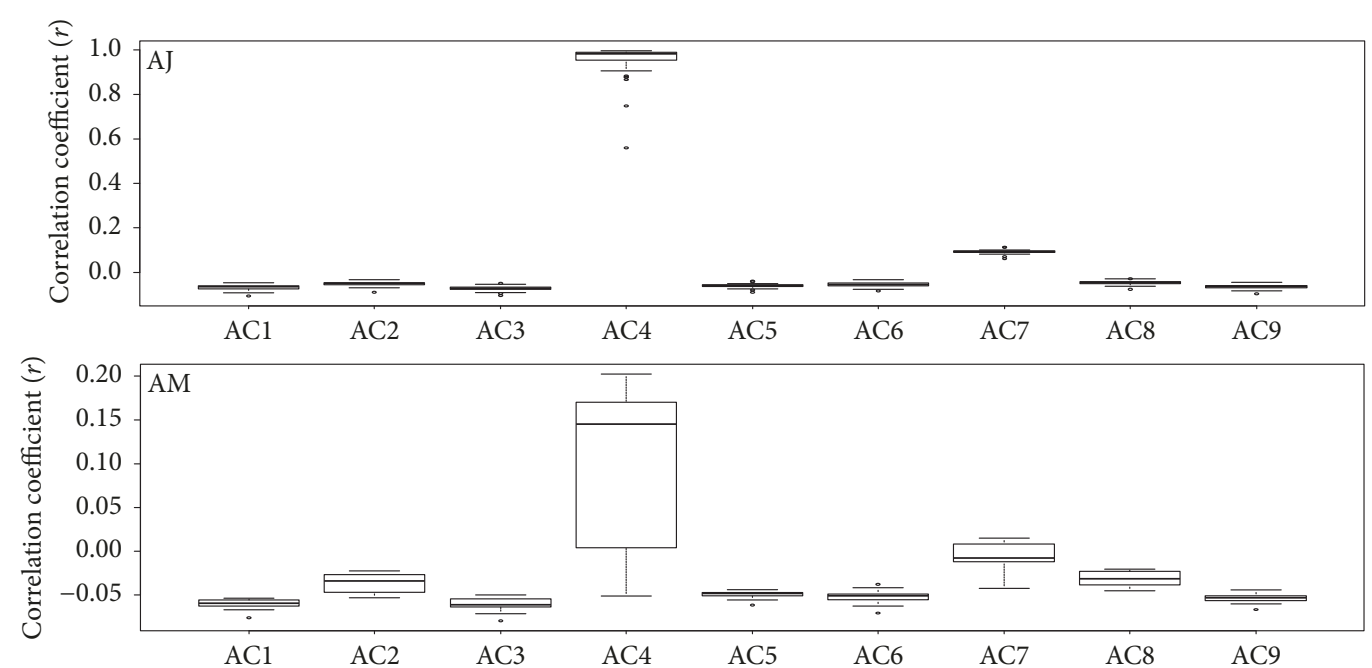

(b)
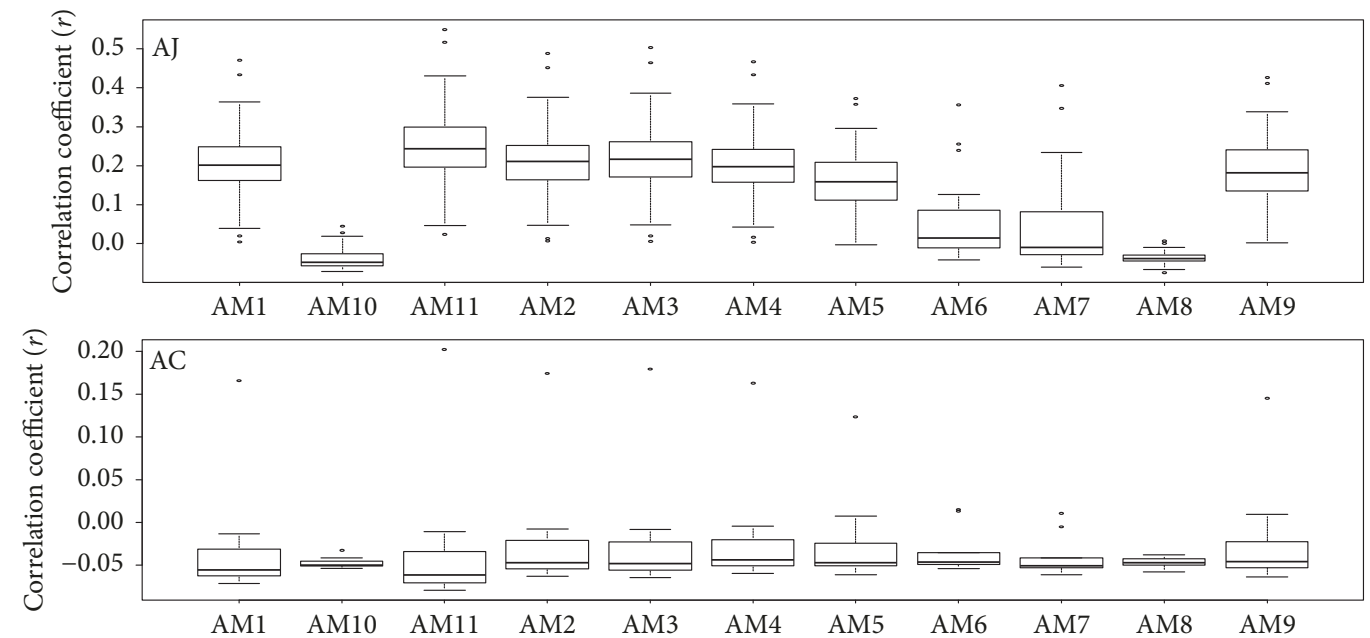

(c)

FIGURE 10: Average coefficients of Pearson's correlation coefficient of Atractylodes samples from methanol extracts. (a) AJ-AC and AJ-AM, (b) AC-AJ and AC-AM, and (c) AM-AJ and AM-AC. AC: A. chinensis Koidz.; AJ: A. japonica Koidz.; AM: A. macrocephala Koidz. 


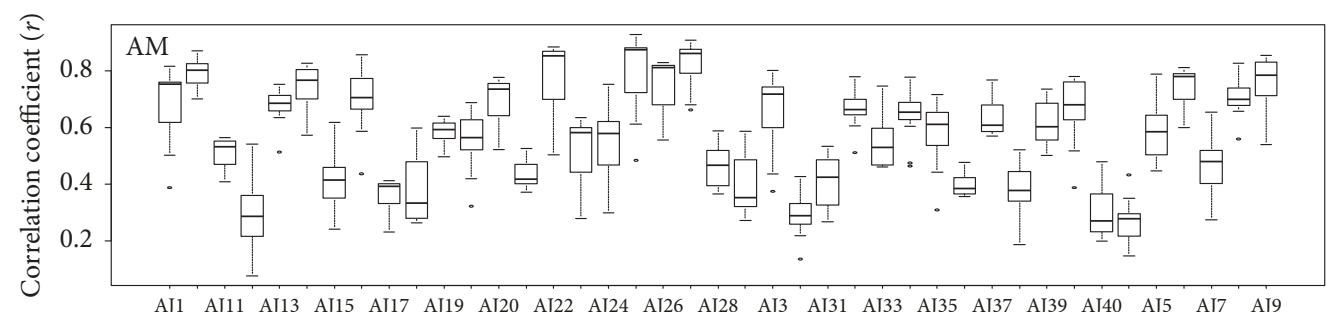

AJ1 AJ11 AJ13 AJ15 AJ17 AJ19 AJ20 AJ22 AJ24 AJ26 AJ28 AJ3 AJ31 AJ33 AJ35 AJ37 AJ39 AJ40 AJ5 AJ7 AJ9

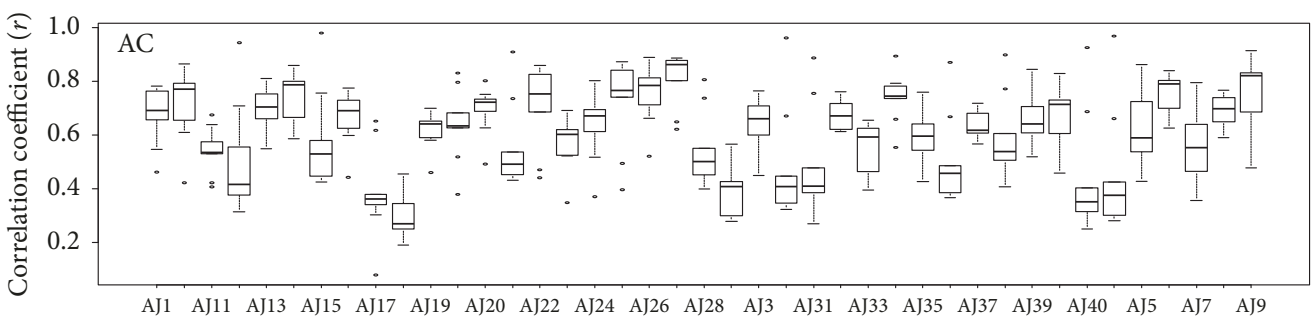

(a)
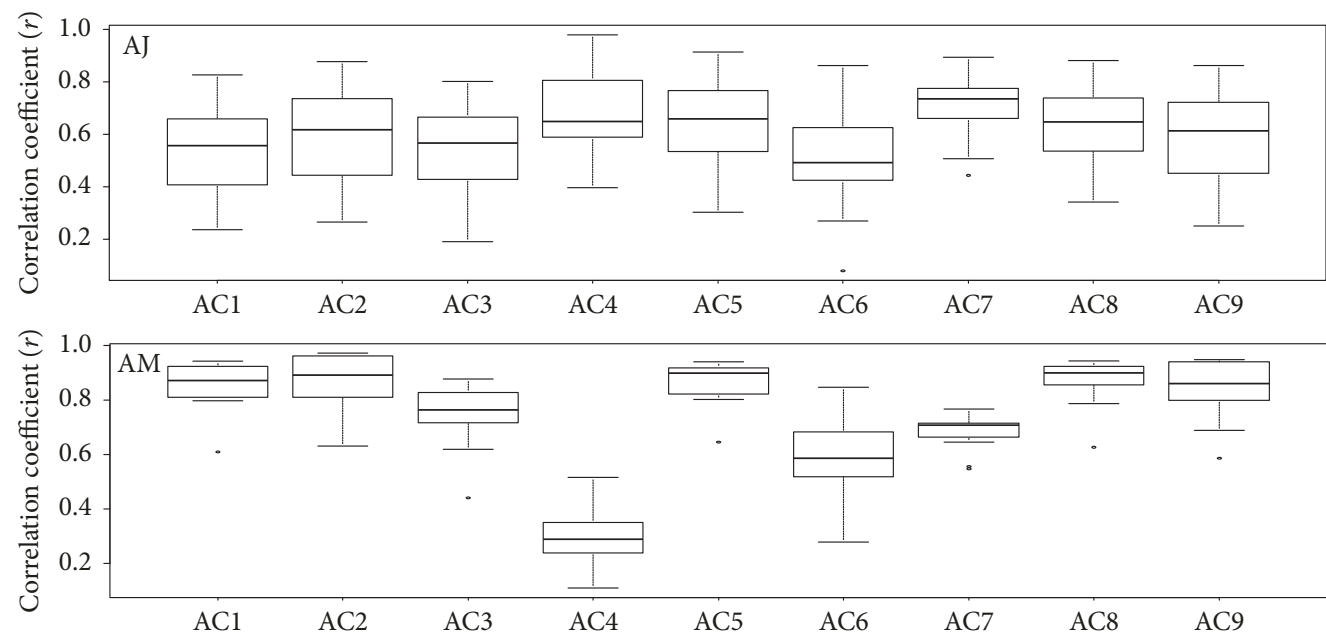

(b)
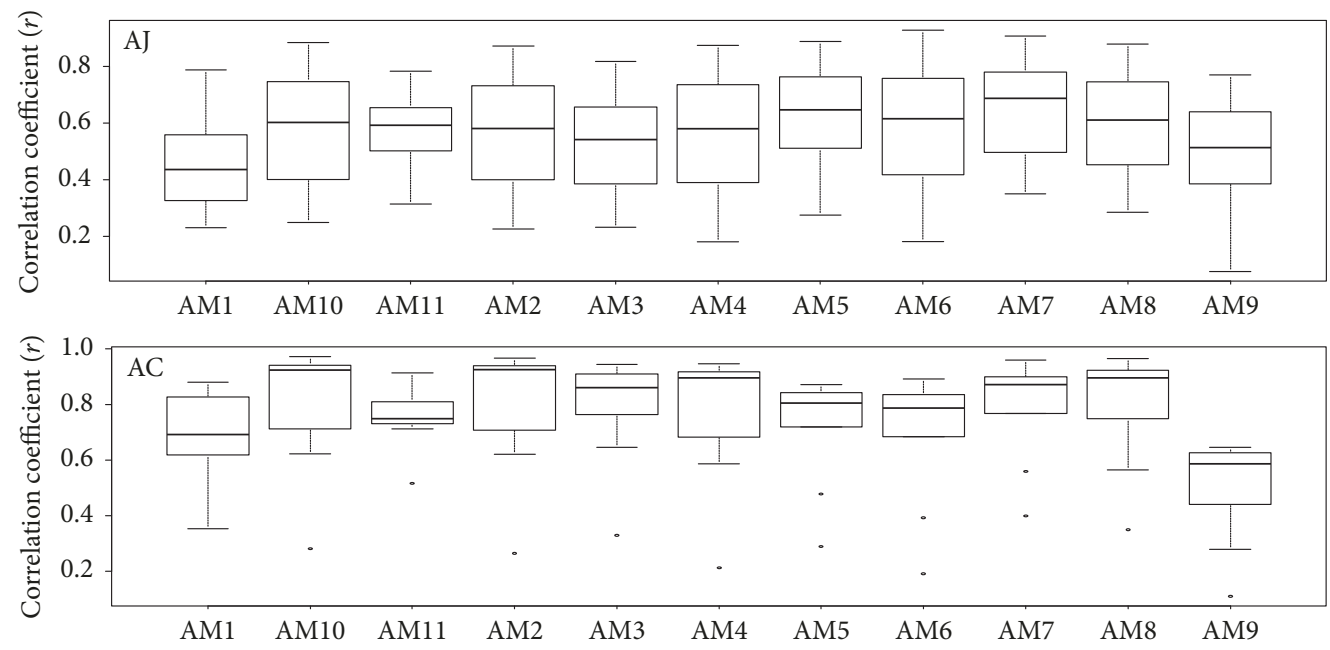

(c)

Figure 11: Average coefficients of Pearson's correlation coefficient of Atractylodes samples from hot-water extracts. (a) AJ-AC and AJ-AM, (b) AC-AJ and AC-AM, and (c) AM-AJ and AM-AC. AC: A. chinensis Koidz.; AJ: A. japonica Koidz.; AM: A. macrocephala Koidz. 


\section{Data Availability}

The data used to support the findings of this study are available from the corresponding author upon request.

\section{Conflicts of Interest}

The authors declare that they have no conflicts of interest.

\section{Authors' Contributions}

J.-H. Kim and E.-J. Doh contributed equally to this work.

\section{Acknowledgments}

This work was supported by the National Research Foundation of Korea (NRF) grant funded by the Korean government (MSIP) (no. 2015R1C1A1A01053466).

\section{Supplementary Materials}

To read our article more intuitively, supplementary material is added as Table S1 and Figures S1 and S2. Table S1: peak number, retention time, relative retention time, and UV absorption wavelength of the reference peak in the chromatograms of the methanol extract and the hot-water extract. Figure S1: average coefficients of Pearson's correlation coefficient of Atractylodes samples from methanol extracts (AJ-AJ, AC-AC, and AM-AM). AC: A. chinensis Koidz.; AJ: A. japonica Koidz.; AM: A. macrocephala Koidz. Figure S2: average coefficients of Pearson's correlation coefficient of Atractylodes samples from hot-water extracts (AJ-AJ, AC-AC, and AM-AM). AC: A. chinensis Koidz; AJ: A. japonica Koidz; AM: A. macrocephala Koidz. (Supplementary Materials)

\section{References}

[1] Korea Food and Drug Administration, The Korean Pharmacopeia, The Korea Food and Drug Administration Notification, 12th, pp. 44, 104 edition, 2017.

[2] The Pharmacopoeia Commission of the Ministry of Health of the People's Republic of China, The Pharmacopoeia of the People's Republic of China, China Science and Technology Press, Beijing, China, 10th, pp. 103, 161 edition, 2015.

[3] E. M. Kang, C. H. Jeong, and K. H. Shim, "Functional properties of Korean Atractylodes japonica Koidz," Korean Journal of PostHarvest Science and Technology of Agricultural Products, vol. 8, pp. 86-91, 2001.

[4] J.-H. Kim, E.-J. Doh, and G. Lee, "Evaluation of medicinal categorization of Atractylodes japonica koidz. by using internal transcribed spacer sequencing analysis and HPLC fingerprinting combined with statistical tools," Evidence-Based Complementary and Alternative Medicine, vol. 2016, Article ID 2926819, 12 pages, 2016.

[5] Y.-Q. Chen, N. Wang, L.-H. Qu, T.-H. Li, and W.-M. Zhang, "Determination of the anamorph of Cordyceps sinensis inferred from the analysis of the ribosomal DNA internal transcribed spacers and 5.8S rDNA," Biochemical Systematics and Ecology, vol. 29 , no. 6, pp. 597-607, 2001.
[6] T. Takamiya, P. Wongsawad, N. Tajima et al., "Identification of Dendrobium species used for herbal medicines based on ribosomal DNA Internal transcribed spacer sequence," Biological \& Pharmaceutical Bulletin, vol. 34, no. 5, pp. 779-782, 2011.

[7] C.-T. Wu, C.-C. Hsieh, W.-C. Lin et al., "Internal transcribed spacer sequence-based identification and phylogenic relationship of I-Tiao-Gung originating from Flemingia and Glycine (Leguminosae) in Taiwan," Journal of Food and Drug Analysis, vol. 21, no. 4, pp. 356-362, 2013.

[8] J. Kang, L. Zhou, J. H. Sun, J. Han, and D.-A. Guo, "Chromatographic fingerprint analysis and characterization of furocoumarins in the roots of Angelica dahurica by HPLC/DAD/ESI-MSn technique," Journal of Pharmaceutical and Biomedical Analysis, vol. 47, no. 4-5, pp. 778-785, 2008.

[9] T. J. White, T. Bruns, S. Lee, and J. Taylor, "Amplification and direct sequencing of fungal ribosomal RNA genes for phylogenetics," in PCR Protocols: A Guide to Methods and Applications, M. A. Innis, D. H. Gelfand, J. J. Sninsky, and T. J. White, Eds., pp. 315-322, Academic Press, New York, NY, USA, 1990.

[10] N. Garcia-Jacas, T. Garnatje, A. Susanna, and R. Vilatersana, "Tribal and subtribal delimitation and phylogeny of the cardueae (Asteraceae): a combined nuclear and chloroplast DNA analysis," Molecular Phylogenetics and Evolution, vol. 22, no. 1, pp. 51-64, 2002.

[11] A. Susanna, N. Garcia-Jacas, O. Hidalgo, R. Vilatersana, and T. Garnatje, "The Cardueae (Compositae) revisited: insights from ITS, trnL-trnF, and matK nuclear and chloroplast DNA analysis," Annals of the Missouri Botanical Garden, vol. 93, no. 1, pp. 150-171, 2006.

[12] M. Shiba, K. Kondo, E. Miki et al., "Identification of medicinal Atractylodes based on ITS sequences of nrDNA," Biological \& Pharmaceutical Bulletin, vol. 29, no. 2, pp. 315-320, 2006.

[13] X.-M. Cheng, T. Zhao, T. Yang, C.-H. Wang, S. W. A. Bligh, and Z.-T. Wang, "HPLC fingerprints combined with principal component analysis, hierarchical cluster analysis and linear discriminant analysis for the classification and differentiation of Peganum sp. indigenous to China," Phytochemical Analysis, vol. 21, no. 3, pp. 279-289, 2010.

[14] J. Lu, J.-S. Wang, and L.-Y. Kong, "Anti-inflammatory effects of Huang-Lian-Jie-Du decoction, its two fractions and four typical compounds," Journal of Ethnopharmacology, vol. 134, no. 3, pp. 911-918, 2011.

[15] J. A. S. Almeida, L. M. S. Barbosa, A. A. C. C. Pais, and S. J. Formosinho, "Improving hierarchical cluster analysis: a new method with outlier detection and automatic clustering," Chemometrics and Intelligent Laboratory Systems, vol. 87, no. 2, pp. 208-217, 2007.

[16] C. Budayan, I. Dikmen, and M. T. Birgonul, "Comparing the performance of traditional cluster analysis, self-organizing maps and fuzzy C-means method for strategic grouping," Expert Systems with Applications, vol. 36, no. 9, pp. 11772-11781, 2009.

[17] Y. Kumooka, "Hierarchical cluster analysis as a tool for preliminary discrimination of ATR-FT-IR spectra of OPP acrylic and rubber-based adhesives," Forensic Science International, vol. 189, no. 1-3, pp. 104-110, 2009.

[18] J. L. R. Júnior and N. Ré-Poppi, "Determination of organochlorine pesticides in ground water samples using solid-phase microextraction by gas chromatography-electron capture detection," Talanta, vol. 72, no. 5, pp. 1833-1841, 2007. 
[19] R. Taylor, "Interpretation of the correlation coefficient: a basic review," Journal of Diagnostic Medical Sonography, vol. 6, no. 1, pp. 35-39, 1990.

[20] U. Ceglarek, B. Casetta, J. Lembcke, S. Baumann, G. M. Fiedler, and J. Thiery, "Inclusion of MPA and in a rapid multidrug LC-tandem mass spectrometric method for simultaneous determination of immunosuppressants," Clinica Chimica Acta, vol. 373, no. 1-2, pp. 168-171, 2006.

[21] M. Goodarzi, P. J. Russell, and Y. V. Heyden, "Similarity analyses of chromatographic herbal fingerprints: a review," Analytica Chimica Acta, vol. 804, pp. 16-28, 2013.

[22] D. Granatoa, J. S. Santos, G. B. Escher, B. L. Ferreira, and R. M. Maggio, "Use of principal component analysis (PCA) and hierarchical cluster analysis (HCA) for multivariate association between bioactive compounds and functional properties in foods: A critical perspective," Trends in Food Science \& Technology, vol. 72, pp. 83-90, 2018.

[23] M. Stone, X. Liu, H. Chen, and J. L. Prince, "A preliminary application of principal components and cluster analysis to internal tongue deformation patterns," Computer Methods in Biomechanics and Biomedical Engineering, vol. 13, no. 4, pp. 493503, 2010.

[24] A. Ben-Hur and I. Guyon, "Detecting stable clusters using principal component analysis," in Functional Genomics: Methods and Protocols, M. J. Brownstein and A. Kohodursky, Eds., pp. 159-182, Humana Press, New York, NY, USA, 2003.

[25] H.-D. Cho, U. Kim, J. H. Suh et al., "Classification of the medicinal plants of the genus Atractylodes using high-performance liquid chromatography with diode array and tandem mass spectrometry detection combined with multivariate statistical analysis," Journal of Separation Science, vol. 39, no. 7, pp. 12861294, 2016.

[26] A. N. Wang, Y. Q. Liu, and Q. Cai, "Study on specific chromatograms and contents of atractylodinol, atractyldtylodin, atractylenolide II in Rhizoma Atractylodis," Chinese Journal of Pharmaceutical Analysis, vol. 36, pp. 91-95, 2016.

[27] O. Takeda, E. Miki, S. Terabayashi et al., "A comparative study on essential oil components of wild and cultivated Atractylodes lancea and A. chinensis," Planta Medica, vol. 62, no. 5, pp. 444449, 1996.

[28] Y.-G. Xia, B.-Y. Yang, Q.-H. Wang, J. Liang, D. Wang, and H.-X. Kuang, "Species classification and quality assessment of Cangzhu (Atractylodis rhizoma) by high-performance liquid chromatography and chemometric methods," Journal of Analytical Methods in Chemistry, vol. 2013, Article ID 497532, 7 pages, 2013.

[29] A. J. Windsor, M. Reichelt, A. Figuth et al., "Geographic and evolutionary diversification of glucosinolates among near relatives of Arabidopsis thaliana (Brassicaceae)," Phytochemistry, vol. 66, no. 11, pp. 1321-1333, 2005.

[30] A. C. Figueiredo, J. G. Barroso, L. G. Pedro, and J. J. C. Scheffer, "Factors affecting secondary metabolite production in plants: volatile components and essential oils," Flavour and Fragrance Journal, vol. 23, no. 4, pp. 213-226, 2008.

[31] L. P. Guo, L. Q. Huang, Y. X. Jiang et al., "Key influencing factors on essential oil components of Atractylodes lancea and study on its division of climate adaptability," China Journal of Chinese Materia Medica, vol. 32, pp. 888-893, 2007.

[32] J. Zhou, F. Qu, and Y. Yu, "Chemical and ecological evaluation of a genuine Chinese medicine: Atractylodes macrocephala Koidz," African Journal of Traditional, Complementary and Alternative Medicines, vol. 8, no. 4, pp. 405-411, 2011.
[33] Z. Ouyang, L. Zhang, M. Zhao et al., "Identification and quantification of sesquiterpenes and polyacetylenes in Atractylodes lancea from various geographical origins using GC-MS analysis," Brazilian Journal of Pharmacognosy, vol. 22, no. 5, pp. 957-963, 2012.

[34] H. Cai, Z. Xu, S. Luo et al., "Study on chemical fingerprinting of crude and processed Atractylodes macrocephala from different locations in Zhejiang province by reversed-phase highperformance liquid chromatography coupled with hierarchical cluster analysis," Pharmacognosy Magazine, vol. 8, no. 32, pp. 300-307, 2012. 


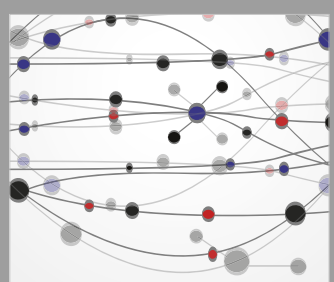

The Scientific World Journal
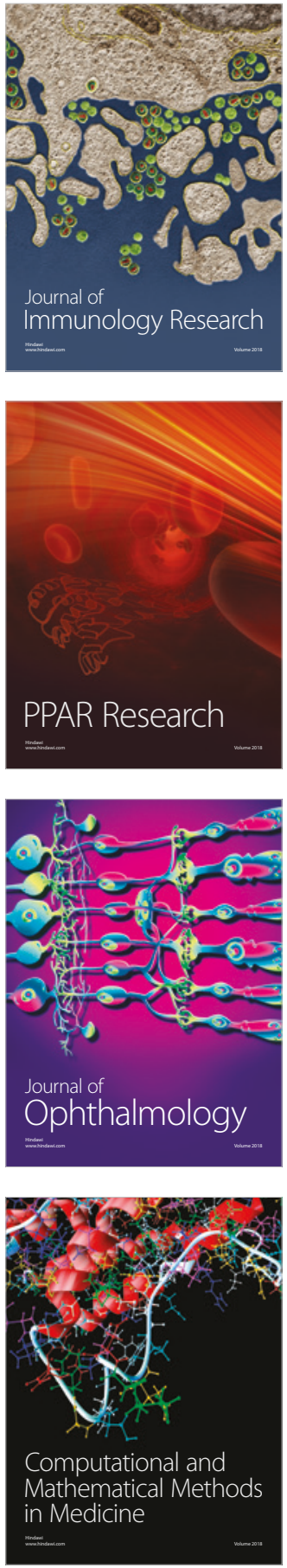

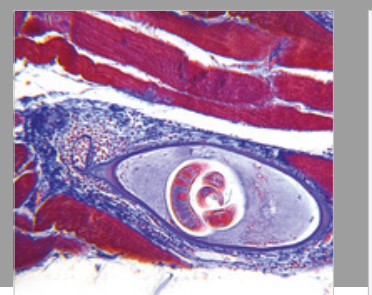

Gastroenterology Research and Practice

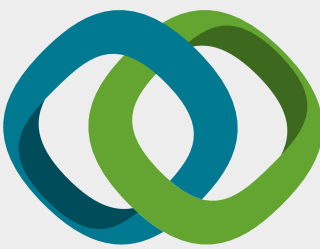

\section{Hindawi}

Submit your manuscripts at

www.hindawi.com
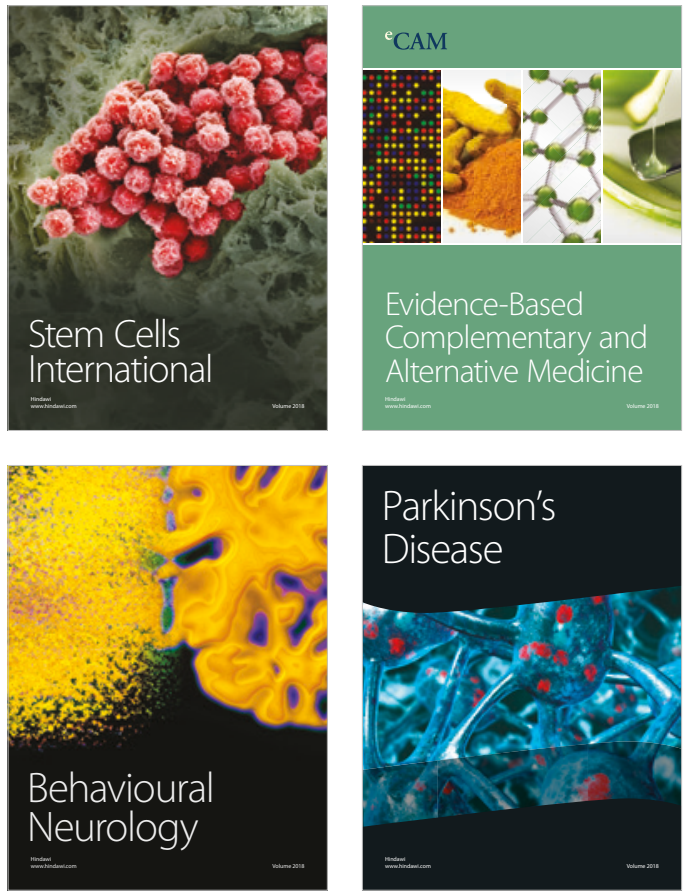

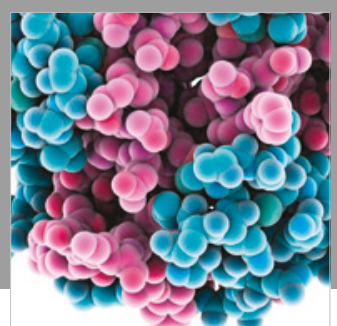

ournal of

Diabetes Research

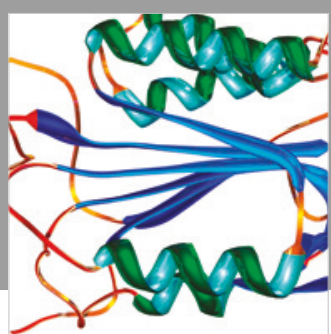

Disease Markers
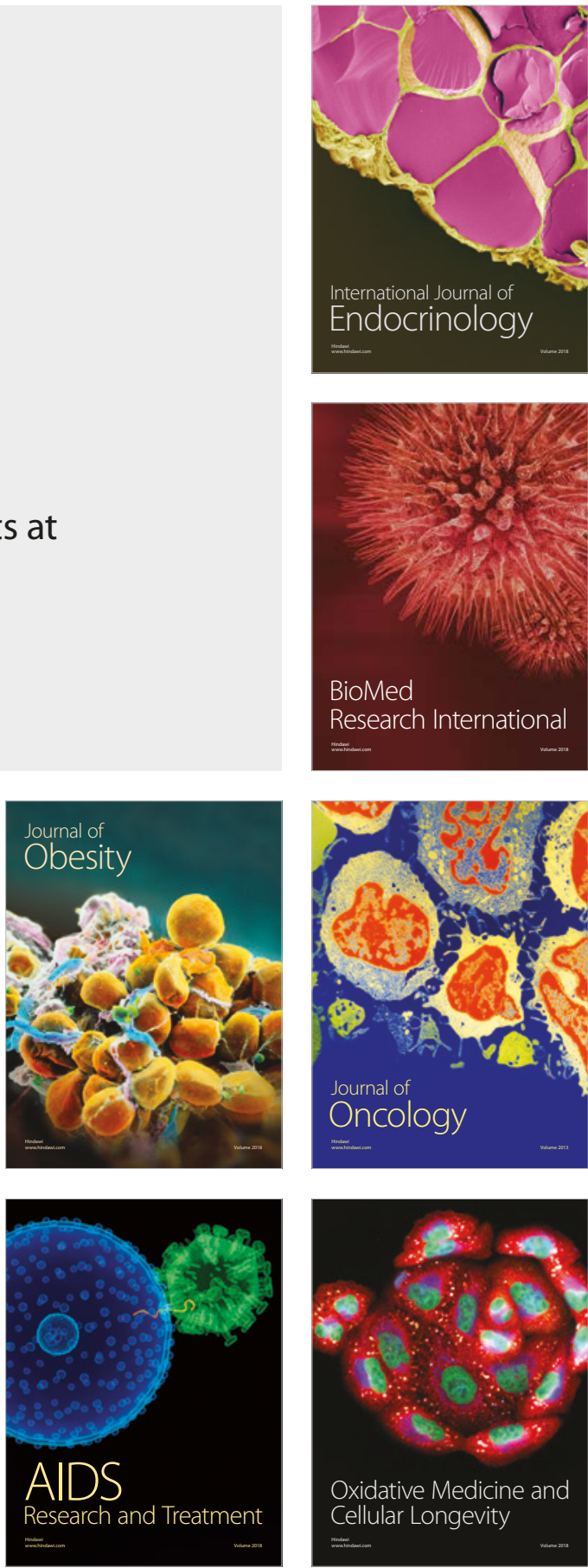